\title{
Targeting tumors with IL-21 reshapes the tumor microenvironment by proliferating PD-1int Tim-3-CD8+ T cells
}

\author{
Sisi Deng, ${ }^{1,2,3,4}$ Zhichen Sun, ${ }^{2}$ Jian Qiao, ${ }^{3}$ Yong Liang, ${ }^{2}$ Longchao Liu, ${ }^{3}$ Chunbo Dong, ${ }^{3}$ Aijun Shen, ${ }^{3}$ \\ Yang Wang, ${ }^{3}$ Hong Tang, ${ }^{5}$ Yang-Xin Fu, ${ }^{3}$ and Hua Peng ${ }^{2}$ \\ ${ }^{1}$ Wuhan Institute of Virology, Chinese Academy of Sciences, Wuhan, China. ${ }^{2}$ Key Laboratory of Infection and Immunity of \\ CAS, Institute of Biophysics, Chinese Academy of Sciences, Beijing, China. ${ }^{3}$ Department of Pathology, University of Texas \\ Southwestern Medical Center, Dallas, Texas, USA. ${ }^{4}$ University of Chinese Academy of Sciences, Beijing, China. ${ }^{5}$ Institute \\ Pasteur of Shanghai Chinese Academy of Sciences, Shanghai, China.
}

The lack of sufficient functional tumor-infiltrating lymphocytes in the tumor microenvironment (TME) is one of the primary indications for the poor prognosis of patients with cancer. In this study, we developed an Erbitux-based IL-21 tumor-targeting fusion protein (Erb-IL21) to prolong the half-life and improve the antitumor efficacy of IL-21. Compared with Erb-IL2, ErbIL21 demonstrated much lower toxicity in vivo. Mechanistically, Erb-IL21 selectively expanded functional cytotoxic T lymphocytes but not dysfunctional CD8+ T cells in the TME. We observed that the IL-21-mediated antitumor effect largely depended on the existing intratumoral CD8 ${ }^{+} \mathrm{T}$ cells, instead of newly migrated CD8+ $T$ cells. Furthermore, Erb-IL21 overcame checkpoint blockade resistance in mice with advanced tumors. Our study reveals that Erb-IL21 can target IL-21 to tumors and maximize the antitumor potential of checkpoint blockade by expending a subset of tumor antigen-specific $\mathrm{CD8}^{+} \mathrm{T}$ cells to achieve effective tumor control.

Conflict of interest: The authors have declared that no conflict of interest exists.

Copyright: (c) 2020, American Society for Clinical Investigation.

Submitted: July 22, 2019 Accepted: March 4, 2020 Published: April 9, 2020.

Reference information: JCI Insight. 2020;5(7):e132000. https://doi.org/10.1172/jci. insight.132000.

\section{Introduction}

The lack of tumor-infiltrating lymphocytes (TILs) has been a significant contributor to the inadequate response to immunotherapies (1-3). Even in tumors enriched with TILs, the dominant existence of dysfunctional $\mathrm{PD}-1^{+} \mathrm{Tim} 3^{+} \mathrm{CD} 8^{+} \mathrm{T}$ cells is an established indicator of the poor prognosis of patients with cancer (4-6).

$\mathrm{T}$ cell-stimulating cytokines play essential roles in $\mathrm{T}$ cell activation and proliferation (7-11). Insufficient $\mathrm{T}$ cell growth factors inside the tumor microenvironment (TME) might contribute to the lack of TILs. Two decades ago, IL-2 was approved by the US FDA to treat metastatic renal cancer, but clinical application has been hindered by its short half-life and severe side effects for most patients. Peg-IL2, with an increased half-life, has been investigated in clinical trials for tumor treatment, but severe toxicity makes it a daunting therapy for patients with cancer (12-14). IL-21 is another cytokine that has been shown to have antitumor effects (15-17). As a $4 \alpha$-helix bundle cytokine produced by CD4 ${ }^{+} \mathrm{T}$ cells and NK T cells, IL-21 exerts pleiotropic functions by facilitating the maturation and enhancing the cytotoxicity of $\mathrm{CD}^{+} \mathrm{T}$ cells and NK cells, promoting the differentiation of memory $\mathrm{CD} 8^{+} \mathrm{T}$ cells and suppressing the induction and function of Tregs (18-25). However, the detailed mechanism for how IL-21 affects dysfunctional CD8 ${ }^{+} \mathrm{T}$ cell subsets in tumors is not clear. Antigen-specific dysfunctional CD8 $8^{+} \mathrm{T}$ cells inside the TME are characterized by reduced responses to tumor antigen restimulation. These $\mathrm{T}$ cells are often paralleled by low proliferative capacity and the impaired production of IFN- $\gamma$, TNF- $\alpha$, and IL-2. Dysfunctional T cells increasingly express inhibitory molecules, including PD-1, LAG-3, TIM-3, and CTLA-4, which may contribute to the loss of $\mathrm{T}$ cell effector functions (26-29). Blocking inhibitory receptor pathways has become a promising strategy for reactivating dysfunctional $\mathrm{CD}^{+} \mathrm{T}$ cells in the tumor to facilitate an adaptive immune response.

Nevertheless, immune checkpoint blockade (ICB) alone is restricted by the limited expansion of some TILs and the high frequency of subsequent resistance (30-35). It is also unclear which population of TILs is preferentially expanded. Moreover, merely releasing braking by blocking checkpoints might not be sufficient to induce strong immunity for tumor regression, especially for tumors with few TILs. 
Previous studies have demonstrated that IL-21 deficiency could induce CD8 ${ }^{+} \mathrm{T}$ cell dysfunction in chronic viral infection, suggesting that IL-21 might play a role in maintaining $\mathrm{T}$ cell function after constant antigen stimulation (36). However, it is unknown whether IL-21 deficiency could impair functional cytotoxic T lymphocytes (CTLs) inside tumors or if exogenous IL-21 could reactivate the dysfunctional CTLs. Previous work of ours showed that intratumoral injection of IL-21 could shift tumor macrophages from an M2 to an M1 phenotype and that this resulted in tumor control (37). Unfortunately, the half-life of IL-21 is also very short $(37,38)$, and the intratumoral administration of recombinant IL-21 is rather difficult to administer for most patients.

In this study, we delineated the mechanism through which the engineered tumor-targeting antibody IL-21 improves T cell-mediated antitumor function inside the TME to achieve effective tumor control, with reduced off-target toxicity and prolonged half-life.

\section{Results}

Tumor targeting is crucial for the antitumor efficacy of IL-21. To study the clinical relevance of intratumoral IL-21 in antitumor prognosis, we analyzed The Cancer Genome Atlas database. We observed that high expression of IL-21 in the TME correlated with enhanced patient survival in skin cutaneous melanoma (Supplemental Figure 1A; supplemental material available online with this article; https://doi.org/10.1172/jci. insight.132000DS1) and head and neck squamous cell carcinoma (Supplemental Figure 1B). We first investigated whether the IL-21-mediated antitumor responses were initiated in the tumor. Using an engineered protein of IL-21 fused to the Fc portion of IgG1 antibody (IL-21-Fc), We compared treatment effects of IL-21 for MC38 tumor in C57B L/6 mice, via two different administration pathways, either intratumor local injection or i.p. systemic injection (Figure 1A). Systemic therapy with IL-21-Fc failed to control tumors, while intratumoral injection slowed the growth of MC38 tumors (Figure 1A), indicating that IL-21 may play a significant role in antitumor activities inside the TME. This result raises the possibility that the targeted delivery of IL-21 to the tumor may enhance antitumor efficacy. To evaluate the importance of tumor targeting for IL-21, we engineered several tumor cell lines expressing chimeric EGFR (cEGFR), in which 6 amino acids of mouse EGFR were replaced by the residues found in human EGFR to allow the binding of antihuman EGFR antibody $(39,40)$. FDA-approved Erbitux (Erb) was chosen to target cEGFR. We generated an Erb-IL21-Fc (Erb-IL21) fusion protein for IL-21 to be precisely delivered into cEGFR tumors by binding directly to $\mathrm{CEGFR}^{+}$tumor cells (Figure 1B). We also designed a negative control fusion protein LA22-IL21Fc (LA22-IL21) with another anti-EGFR antibody (LA22) that binds to WT EGFR but not cEGFR on tumors (Figure 1B). The purified IL-21-Fc and Erb-IL21 were analyzed by SDS-PAGE, which verified the high purity of these IL-21 fusion proteins (Supplemental Figure 2A). The binding of Erb-IL21 was tested by incubating with $\mathrm{cEGFR}^{+}$tumors cells in vitro, and the efficient binding of IL-21 to cEGFR ${ }^{+}$cells was confirmed by anti-mouse IL21-APC staining. (Supplemental Figure 2B). Subsequently, to further confirm whether the fusion protein targets $\mathrm{CEGFR}^{+}$tumors specifically in vivo, C57BL/6 mice were inoculated with $\mathrm{cEGFR}^{+}$(MC38-cEGFR) cells in the right flank and cEGFR ${ }^{-}$(MC38) cells in the left flank. The mice were then i.v. treated with Cy5.5-labeled Erb-IL21 or LA22-IL21 at the same dose. Untreated mice were used as controls. Indeed, fluorescent photography data showed that Erb-IL21 accumulated substantially more fluorescence in $\mathrm{CEGFR}^{+}$tumors (right) than in $\mathrm{CEGFR}^{-}$tumors (left). In contrast, LA22-IL21 was detected at a much lower level of fluorescent intensity in cEGFR ${ }^{+}$tumors (Figure 1, C and D). This result confirms the essential role of Erb in the tumor targeting of Erb-IL21 in vivo. To investigate whether Erb-IL21 could enhance antitumor effects through the targeted delivery of IL-21 to cEGFR ${ }^{+}$tumors, we i.p. treated mice bearing MC38-cEGFR tumors with the same molecular IL-21 dose of Erb-IL21, LA22-IL21, or IL-21-Fc. We observed that Erb-IL21 effectively controlled tumor growth, while LA22-IL21 and IL-21-Fc did not (Figure 1E). These data suggest that the therapeutic effects of tumor-targeted Erb-IL21 were much more potent than those of nontargeted LA22-IL21 or IL-21-Fc. To exclude the possibility that the antitumor effect is caused by immune responses against human EGFR in the tumor, we further monitored Erb-IL21 therapy in EGFR-Tg mice, which constitutively express human EGFR. These mice were obtained by cross-breeding EGFR-Tg mice with WT C57BL/6 mice for 10 generations. The immune cells in EGFR-Tg mice tolerate both mouse and human EGFR and do not mount an immune response against the cEGFR (41). Consistent with previous results, Erb-IL21 also inhibited tumor growth in EGFR-Tg mice (Figure 1F). Altogether, these results suggest that the tumor regression induced by Erb-IL21 resulted from tumor-targeting IL-21 but was not due to cEGFR antigenicity. 


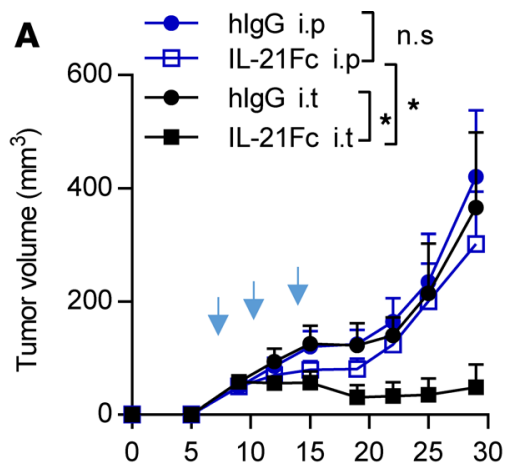

Days after tumor innoculation

C
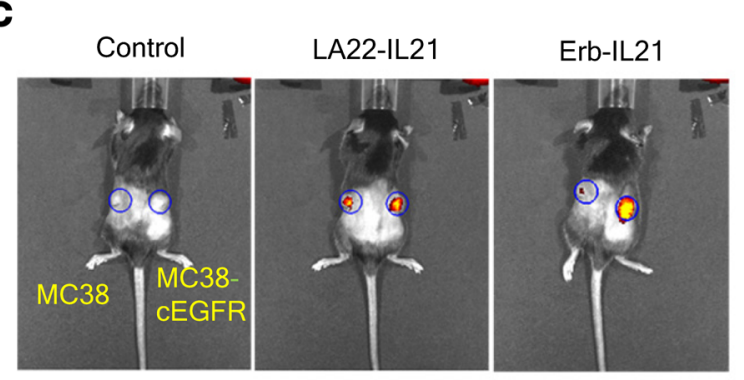

E

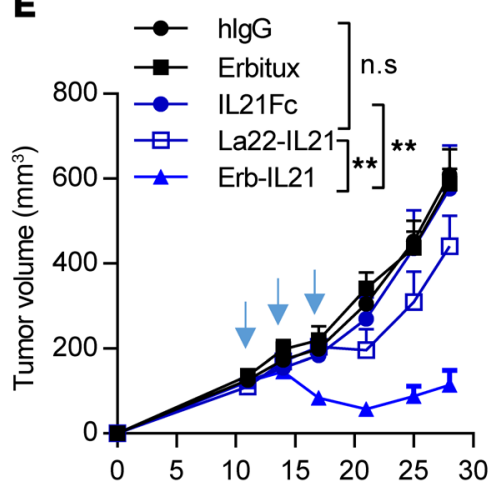

Days after tumor innoculation
Epi-fluorescence

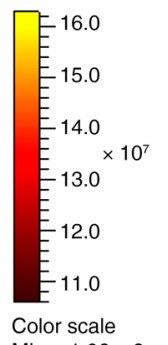

Min $=1.06 \times 8$

$\operatorname{Max}=1.63 \times 8$

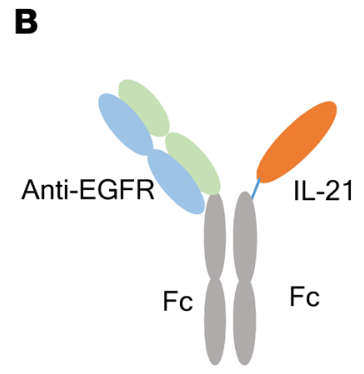

LA22-IL21

$\mathbf{F}$

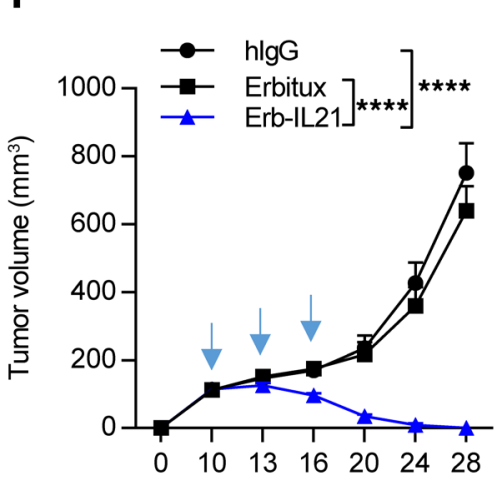

Days after tumor innoculation

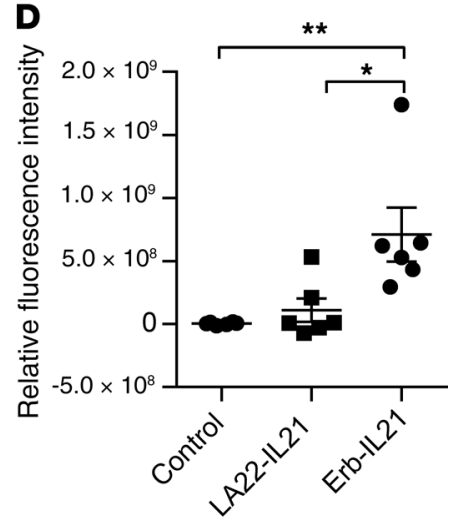

Erb-IL21

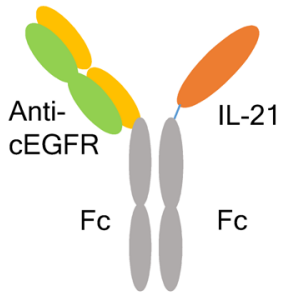


Erb-IL21 could control tumors at a dose of $25 \mu \mathrm{g}$ and achieved tumor eradication at $75 \mu \mathrm{g}$ and $225 \mu \mathrm{g}$ (Supplemental Figure 4A). Moreover, we determined that even at a dose of $225 \mu \mathrm{g}$, no apparent toxicity was observed for Erb-IL21 (Supplemental Figure 4, B-D).

Beyond the activation of $\mathrm{CD}^{+} \mathrm{T}$ cells, IL-21 can suppress Tregs (42-44). In contrast, IL-2, a cytokine widely evaluated in preclinical and clinical studies, promotes both CD8 $8^{+} \mathrm{T}$ cells and Tregs (45-47). We speculated that these 2 cytokines are comparable in antitumor effects and toxicity when delivered systemically. MC38-cEGFR tumor-bearing mice were i.p. injected with the same dose of either Erb-IL21 or ErbIL2 on day 11 after tumor inoculation. We observed that Erb-IL2 could limit tumor growth at a dose of 25 $\mu \mathrm{g}$, similar to the effect of Erb-IL21 (Figure 2A). As shown in previous studies, IL-2 results in severe side effects (48-50). We further compared the toxicity of Erb-IL21 with that of Erb-IL2 by measuring changes in body weight and the levels of serum cytokines after treatment. We observed that $25 \mu \mathrm{g}$ Erb-IL2, but not Erb-IL21, resulted in significant weight loss compared with that of the untreated mice 6 days after initial treatment (Figure 2B).

Additionally, $25 \mu \mathrm{g}$ Erb-IL2 led to high concentrations of MCP-1, TNF- $\alpha$, and IFN- $\gamma$ in the blood, while Erb-IL21 did not result in any detectable presence of inflammatory cytokines (Supplemental Figure 5, A-C). When the mice were treated with $75 \mu \mathrm{g}$ Erb-IL2 versus Erb-IL21, Erb-IL2 resulted in a sharp weight loss and even mouse death 4 days after the initial treatment, while Erb-IL21 did not influence body weight (Figure 2C). Moreover, the survival percentage after Erb-IL2 treatment rapidly decreased due to toxicity, while Erb-IL21 treatment maintained a long term and high percentage of survival (4 of 5 mice) (Figure 2D). Collectively, our data revealed that Erb-IL21 is an efficient and safe cytokine to be used in tumor treatment.

Tumor regression induced by $I L-21$ depends on $C D 8^{+} T$ cells. Next, we performed a series of experiments to determine the antitumor activity of the Erb-IL21 fusion protein in different tumor models, including MC38-cEGFR, B16-cEGFR, and Ag104Ld-cEGFR. C57BL/6 mice bearing cEGFR ${ }^{+}$tumors were i.p. treated with $75 \mu \mathrm{g}$ Erb-IL21 3 times within a week. An impressive antitumor effect of Erb-IL21 was observed in all tumor models (Supplemental Figure 6, A-C), suggesting that Erb-IL21 may be widely applied for the treatment of different kinds of tumors.

IL-21 can reactivate and expand NK cells $(7,51,52)$ and shift macrophages from an M2 to an M1 phenotype (37). To explore whether innate immune cells play essential roles in antitumor treatment by Erb-IL21, we inoculated C57BL/6 mice with MC38-cEGFR tumor cells. Ten days later, the mice were i.p. treated with $75 \mu \mathrm{g}$ Erb-IL21, and NK cells and macrophages were depleted using anti-NK1.1 and anti-CSF1R antibody treatment, respectively. We observed that the depletion of these cells did not affect the antitumor capacity of Erb-IL21, indicating that the therapeutic effect mediated by Erb-IL21 may require adaptive immunity (Figure 3A). To evaluate the essential role of adaptive immunity during ErbIL21 treatment, we inoculated Rag-1-deficient mice with MC38-cEGFR and i.p. treated them with $75 \mu \mathrm{g}$ Erb-IL21. Indeed, Erb-IL21 was unable to inhibit tumor growth in Rag-1-deficient mice (Supplemental Figure $6 \mathrm{D}$ ). To determine if $\mathrm{T}$ cells are required for IL-21-mediated tumor control, we depleted CD4 ${ }^{+} \mathrm{T}$ or $\mathrm{CD}^{+} \mathrm{T}$ cells during Erb-IL21 treatment. We observed that the antitumor effect of Erb-IL21 was abolished after depleting $\mathrm{CD} 8^{+} \mathrm{T}$ cells, while the deficiency of $\mathrm{CD}^{+} \mathrm{T}$ cells did not affect tumor regression (Figure 3B). We further analyzed the amount of $\mathrm{CD}^{+} \mathrm{T}$ cells in tumors by flow cytometry on day 5 after Erb-IL21 treatment. Compared with the Erbitux group, the percentage of CD8 ${ }^{+} \mathrm{T}$ cells in tumor-infiltrating $\mathrm{T}$ cells increased in mice receiving i.p. treatment of Erb-IL21 but not LA22-IL21. The number of $\mathrm{CD}^{+} \mathrm{T}$ cells increased in mice treated with Erb-IL21 and LA22-IL211 (Figure 3, C and D). IL-21 can potently augment the frequency and enhance the activity of antigen-specific CTL responses (53). IFN- $\gamma$ is the crucial cytokine released by functional $\mathrm{T}$ cells and is an evaluating marker of antigen-specific $\mathrm{T}$ cell responses to tumors. To investigate whether tumor-targeting IL-21 enhances the function of CD8 ${ }^{+}$ T cells more effectively than when IL-21 was not targeted to the tumors, we compared CTLs induced by the i.p. injection of Erb-IL21 and LA22-IL21. The frequency of IFN- $\gamma^{+} \mathrm{CD} 8^{+} \mathrm{T}$ cells in the TME was significantly increased after Erb-IL21 but not LA22-IL21 treatment (Figure 3E). This finding indicates that tumor-targeting IL-21 can increase functional T cells in immunogenic tumors.

Preexisting intratumoral CTLs are essential and sufficient for Erb-IL21 therapy. Systemic Erb-IL21-induced tumor control can depend on either preexisting TILs in the tumor or newly arriving TILs, such as primed cells from drain lymph nodes. To distinguish tumor-resident $\mathrm{T}$ cells from peripheral $\mathrm{T}$ cells migrated into tumors, MC38-cEGFR tumor-bearing mice were treated with FTY720 during Erb-IL21 i.p. treatment to 


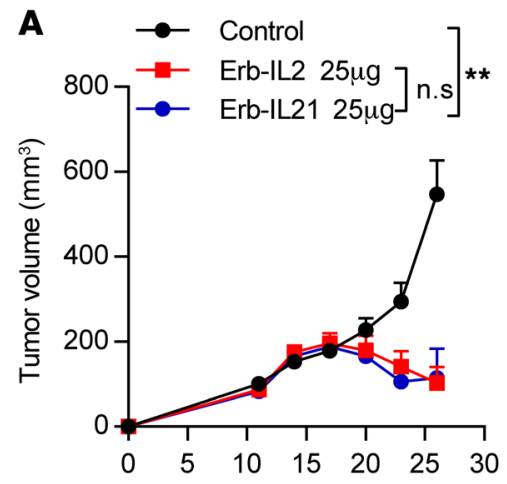

Days after tumor innoculation

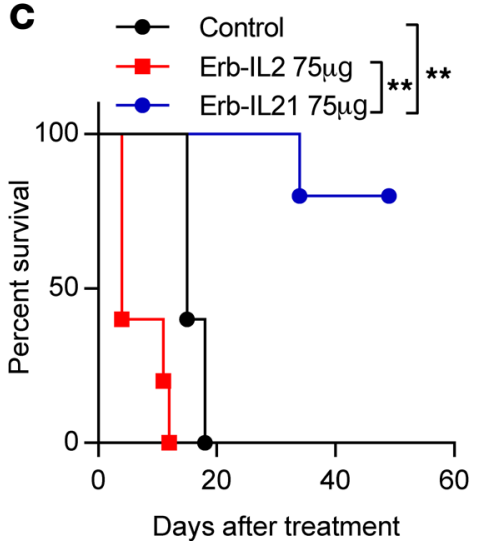

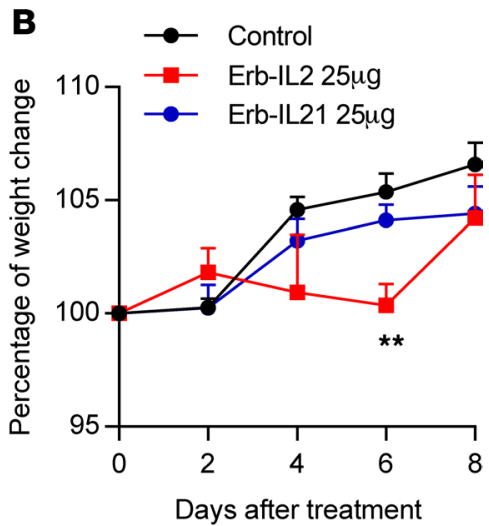

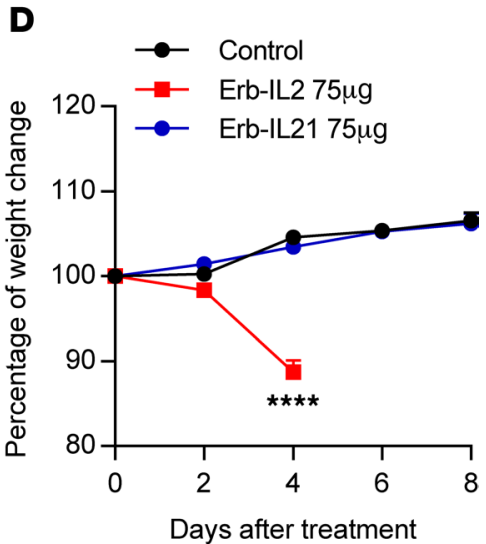

Figure 2. Erb-IL21 presents the same antitumor potency as Erb-IL2. (A and B) Tumor-bearing C57BL/6 mice $(n=5)$ were inoculated with $3 \times 10^{5}$ MC38-cEGFR cells on day 0 and were i.p. treated with $25 \mu \mathrm{g}$ Erb-IL21 or Erb-IL2 on days 11, 14, and 17. Mice without treatment are designated as the control. (A) Tumor growth curve. Tumor growth was measured and compared twice weekly. (B) Body weight change in mice. (C and D) Tumor-bearing C57BL/6 mice $(n=5)$ were inoculated with $3 \times 10^{5}$ MC38-cEGFR cells on day 0 and were i.p. treated with $75 \mu$ grb-IL21 or Erb-IL2 on days 11, 14, and 17. Mice without treatment were designated as the control. (C) Body weight change in mice. (D) Survival curve. The mean \pm SEM values are shown. Two-way ANOVA tests were used to analyze the tumor growth data, and unpaired $t$ tests were used to analyze the other data. ${ }^{* *} P<0.01,{ }^{* * *} P<0.0001$. One of two representative experiments is shown.

diminish peripheral T cell migration. FTY720 is a small-molecule analog of sphingosine 1-phosphate (S1P) that induces the internalization and degradation of the S1P receptor to prevent lymphocyte egress from the lymph nodes (54). Despite a dramatic reduction in circulating PBMCs after FTY720 treatment, there was no change in the antitumor efficacy of Erb-IL-21. This result suggests that $\mathrm{T}$ cells that had infiltrated the tumor before FTY720 treatment were sufficient to generate the antitumor response (Figure 4A). Furthermore, when anti-CD8 was given i.p. to mice for depletion of CD8 $8^{+} \mathrm{T}$ cells during FTY720 and Erb-IL21 treatment, the therapeutic effects of Erb-IL21 were abrogated (Figure 4A). These data imply that preexisting tumor-infiltrating $\mathrm{CD} 8^{+} \mathrm{T}$ cells are sufficient in Erb-IL21 treatment.

IL-21 is also reported to increase the frequency of memory $\mathrm{T}$ cells $(20,55)$. We used 3 different approaches to assess the development of immunological memory after treatment with Erb-IL21. To determine whether Erb-IL21 treatment has a prolonged protective effect on impeding the growth of dormant residual cancer, we rechallenged WT and EGFR-Tg mice that underwent complete tumor regression after Erb-IL21 treatment with a lethal dose of MC38-cEGFR cells. All of these mice were completely resistant to tumor challenge (Figure 4, B and C). In our next approach, we tested the tumor-specific CD8 ${ }^{+} \mathrm{T}$ cell response in the lymph nodes of MC38-cEGFR tumor-bearing mice treated with Erb-IL21 and control proteins. Five days after the last treatment, IFN- $\gamma$-secreting cells were evaluated by ELISPOT after in vitro stimulation with the same tumor strain of MC38-cEGFR or irrelevant B16 cells. We observed that stimulation with MC38-cEGFR but not B16 cells resulted in significantly increased IFN- $\gamma$-producing $\mathrm{CD}^{+} \mathrm{T}$ cells from mice treated with targeting Erb-IL21, compared with those not targeted with LA22-IL21 (Figure 4D). These data suggest that Erb-IL21-treated mice had acquired protective memory immunity. 
A

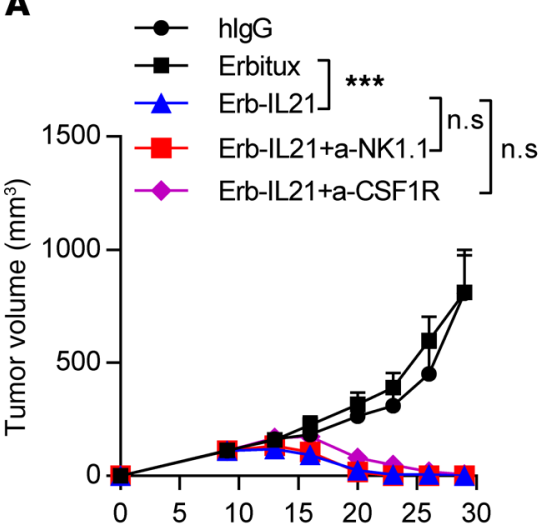

Days after tumor innoculation

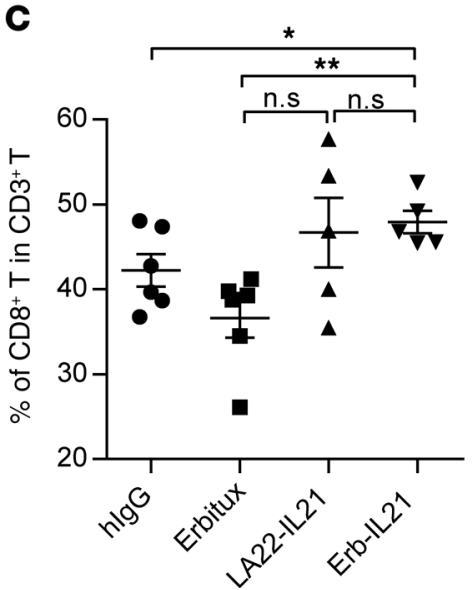

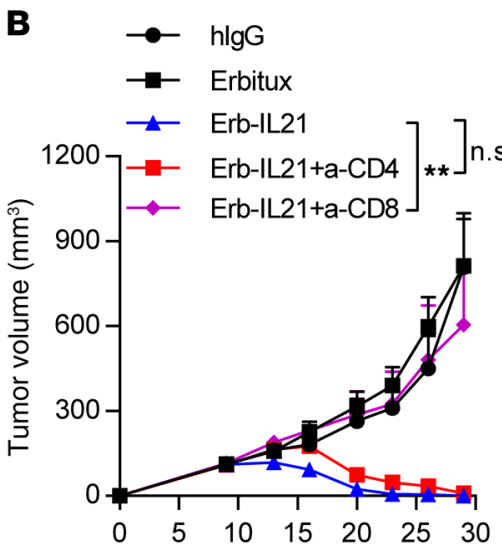

Days after tumor innoculation

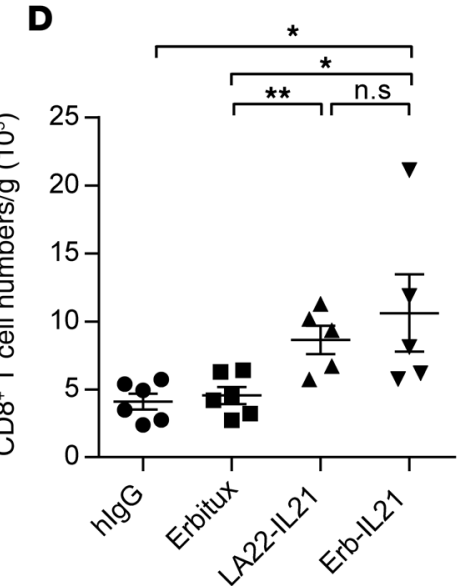

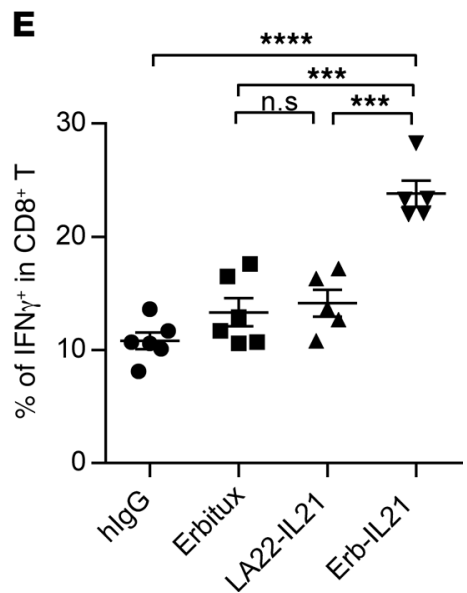

Figure 3. Tumor regression induced by IL-21 depends on CD8 ${ }^{+}$T cells. C57BL/ 6 mice $(n=4-5)$ were inoculated with $2.5 \times 10^{5}$ MC38-cEGFR cells and were i.p. treated with $75 \mu \mathrm{g}$ hlgG, Erbitux, or Erb-IL21 on days 10, 13, and 16. (A) Mice were i.p. treated with $400 \mu \mathrm{g}$ anti-NK1.1 antibody on days 9 and 14 or 300 $\mu \mathrm{g}$ anti-CSF1R on days 9, 12, 15 and 18. One of two representative experiments is shown. (B) Mice were i.p. treated with $200 \mu \mathrm{g}$ anti-CD4 antibody or antiCD8 antibody on days $9,12,15$, and 18. One of two representative experiments is shown. (C-E) Tumor tissues were analyzed 5 days after i.p. treatment of $40 \mu \mathrm{g} \mathrm{hlgG,} \mathrm{Erbitux,} \mathrm{LA22-IL21,} \mathrm{or} \mathrm{Erb-IL21} \mathrm{or} \mathrm{control} \mathrm{antibody.} \mathrm{Six} \mathrm{hours} \mathrm{before} \mathrm{sacrifice,} \mathrm{mice} \mathrm{were} \mathrm{i.v.} \mathrm{treated} \mathrm{with} 250 \mu \mathrm{g}$ BFA to enhance intracellular cytokine staining signals by blocking transport processes during cell activation. (C) Percentage of CD8 ${ }^{+} T$ cells in $C D 3^{+} T$ cells. (D) Total cell number of CD8 ${ }^{+}$ T cells per gram tumor. (E) Percentage of IFN- $\gamma^{+}$in CD8 ${ }^{+} \mathrm{T}$ cells. The mean $\pm \mathrm{SEM}$ values are shown. Two-way ANOVA tests were used to analyze the tumor growth data and unpaired $t$ tests were used to analyze the other data. ${ }^{*} P<0.05,{ }^{* *} P<0.01,{ }^{* *} P<0.0001,{ }^{* * * *} P<0.0001$.

Finally, we examined whether the CTLs induced by Erb-IL21 could control a distal tumor. We used a double-tumor model in which the in situ tumor was cEGFR ${ }^{+}$and the distal tumor was cEGFR ${ }^{-}$. We intratumorally treated the $\mathrm{CEGFR}^{+}$tumor with $20 \mu \mathrm{g}$ Erb-IL21 and measured the volume of the distal $\mathrm{EGFR}^{-}$tumor. Erb-IL21 not only controlled the growth of the in situ tumor (Figure 4E) but also arrested the progression of the distal tumor (Figure 4F). These results indicate that Erb-IL21 treatment establishes a memory T cell antitumor response and that Erb-IL21-induced CTLs can limit the growth of remote tumors.

To investigate whether IL-21 can regulate tumor antigen-specific CD8 ${ }^{+} \mathrm{T}$ cells, we assessed the changes of tumor-specific T cells inside the TME after local delivery of IL-21. To better track tumor-specific T cell responses, we treated mice harboring established OVA-expressing MC38 tumors (MC38-OVA) with intratumorally delivery of Erb-IL21. Tumor $\mathrm{CD}^{+} \mathrm{T}$ cells were detected via flow cytometry. Compared with the control group, both the ratio and number of $\mathrm{CD}^{+} \mathrm{T}$ cells increased after Erb-IL21 treatment on day 5 (Supplemental Figure 7, A and B). IFN- $\gamma$-producing $C D 8^{+} \mathrm{T}$ cells, as the functional CTLs, were also significantly increased (Supplemental Figure 7, C and D). This result indicates that IL-21 treatment enhanced the function of $\mathrm{CD}^{+} \mathrm{T}$ cells. To determine the tumor antigen-specific $\mathrm{T}$ cell response, we analyzed OVA-responsive $\mathrm{T}$ cells by a tetramer-staining assay. We observed that, compared with the control group, both the frequency and the total number of OVA-specific CD8 ${ }^{+} \mathrm{T}$ cells were also increased in tumors 5 days after initial IL-21 treatment (Supplemental Figure 7, E and F). Together, these data demonstrate that tumor-targeted delivery 


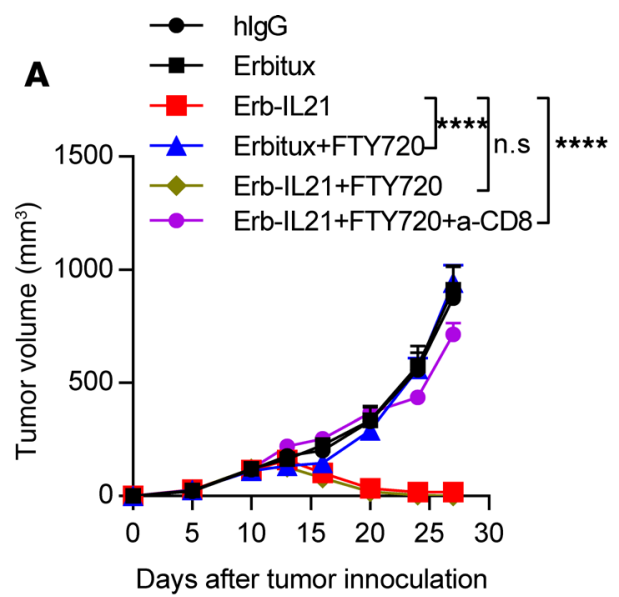

B

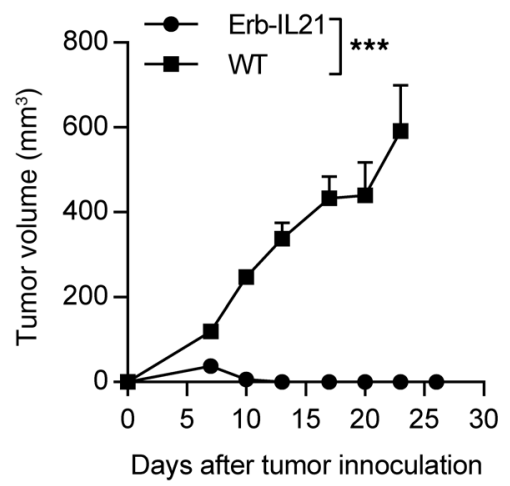

$\mathbf{E}$

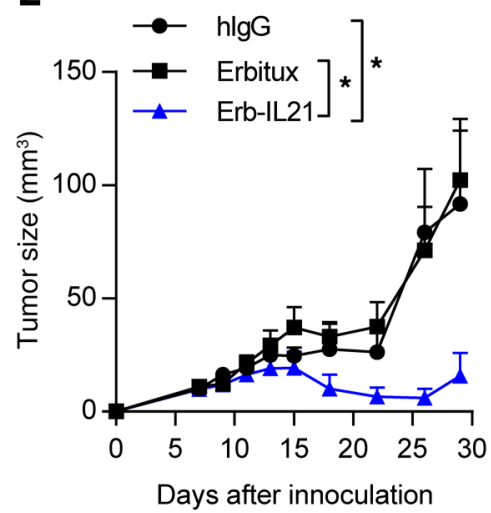

C

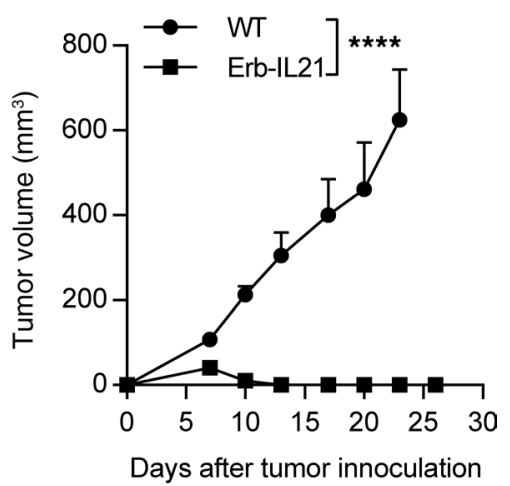

$\mathbf{F}$

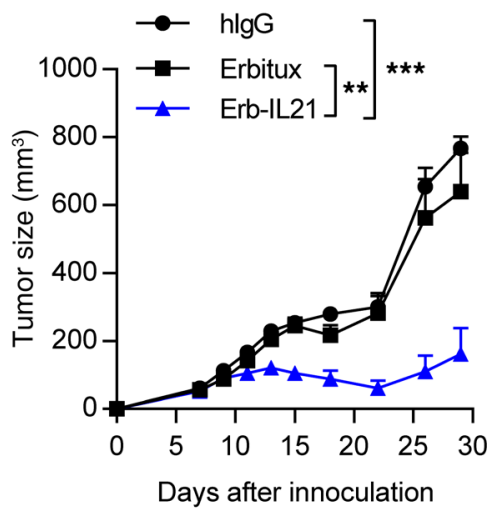

Figure 4. The antitumor effect of Erb-IL21 relies on preexisting intratumoral CD8+ CTLs and can generate a memory response. $(A)$ Mice $(n=5-6)$ were inoculated with $2.5 \times 10^{5} \mathrm{MC} 38$-cEGFR cells and were i.p. treated with $75 \mu \mathrm{g}$ hlgG, anti-EGFR, or Erb-IL21 on days 10, 13, and 16. Mice were i.p. treated with $25 \mu \mathrm{g}$ FTY720 1 day before treatment and every other day after treatment 5 times, and anti-CD8 antibody was i.p. injected $200 \mu \mathrm{g}$ on days $9,12,15$ and 18 . (B) Approximately 30 days after tumor rejection by Erb-IL21 treatment, the tumor-free mice $(n=5)$ were inoculated with $2.5 \times 10^{6}$ MC38-cECFR cells for the tumor-rechallenge assay. Naive WT C57BL/6 mice $(n=5)$ were used as control. (C) Approximately 30 days after tumor rejection in Erb-IL21-treated EGFR-Tg mice $(n=5)$, the tumor-free mice were injected with $2.5 \times 10^{6}$ MC38-cEGFR cells for the tumor-rechallenging assay. Naive EGFR-Tg mice were used as control. (D) Total drain lymph node cells from MC38-cEGFR tumor-bearing mice $(n=5-6)$ were stimulated with repeated freezing-thawing MC38-cEGFR or B16 tumor cells for 48 hours after control or Erb-IL21 treatment on day 20. IFN- $\gamma$-producing cells were enumerated by ELISPOT assay. Results are expressed as the number of spots $/ 5 \times 10^{5}$ splenocytes. (E and F) C57BL/6 mice $(n=4-5)$ were inoculated with $1.5 \times 10^{5}$ MC38-cEGFR cells on the right flank of mice as in situ tumors and $0.5 \times 10^{5} \mathrm{MC} 38$ cells on the left flank as distal tumors. They were intratumorally treated with $20 \mu \mathrm{g}$ hlgG, Erbitux, and ErbIL21 in MC38-CEGFR tumors on days 7, 9, 11, and 13. Tumor growth was measured and compared twice weekly. The mean \pm SEM values are shown. Two-way ANOVA tests were used to analyze the tumor growth data and unpaired $t$ tests were used to analyze the other data. ${ }^{*} P<0.05,{ }^{* *} P<0.01,{ }^{* * *} P<0.0001$, **** $P<0.0001$. One of two representative experiments is shown.

of IL-21 leads to a further increase in the antigen-specific T cell response and cytokine production. We also observed that the frequency of Ki-67+ OVA-specific $\mathrm{CD} 8^{+} \mathrm{T}$ cells was enhanced after IL-21 treatment, indicating potential $\mathrm{T}$ cell proliferation (Supplemental Figure 7G). Besides, the ratio of $\mathrm{CD} 8^{+} \mathrm{T}$ cells to Tregs in tumors was increased after Erb-IL21 treatment (Supplemental Figure 7H). These data suggest that IL-21 might promote $\mathrm{CTL}$ function by augmenting tumor antigen-specific $\mathrm{CD} 8^{+} \mathrm{T}$ cells.

IL-21 resulted in a lower level of PD-1 on tumor antigen-specific $C D 8^{+} T$ cells. IL-21 was reported to reverse the innate NK cell dysfunction in tumors (56). We wondered whether IL-21 could also affect the adaptive dysfunctional $\mathrm{CD} 8^{+} \mathrm{T}$ cells and tested antigen-specific $\mathrm{T}$ cell responses after IL-21 treatment using MC38-OVA. As one of the most overexpressed inhibitory receptors in dysfunctional CD8 $8^{+} \mathrm{T}$ cells, $\mathrm{PD}-1$ in intratumoral $\mathrm{CD} 8^{+} \mathrm{T}$ cells is associated with functional impairment in tumor and chronic infection immune responses (57-59). Thus, based on PD-1 expression, we divided antigen-specific CD8 ${ }^{+} \mathrm{T}$ cells into 3 subgroups: cells with the highest $\mathrm{PD}-1$ expression $\left(\mathrm{PD}-1^{\mathrm{hi}}\right)$, cells with intermediate expression 
$\left(\mathrm{PD}-1^{\mathrm{int}}\right)$, and $\mathrm{PD}-1^{-}$cells. To monitor the influence of Erb-IL21 on antigen-specific $\mathrm{CD} 8^{+} \mathrm{T}$ status in the TME, we tested the mean fluorescence intensity (MFI) of PD-1 in MC38-OVA tumors. We observed that the MFI of PD-1 in OVA-specific CD8 ${ }^{+} \mathrm{T}$ cells was reduced after Erb-IL21 treatment (Figure 5A). We proposed 4 possible pathways for the MFI reduction of PD-1 in CD8 ${ }^{+} \mathrm{T}$ cells after IL-21 treatment: (a) migration of new PD-1- $\mathrm{T}$ cells; (b) IL-21-induced apoptosis of $\mathrm{PD}-1^{+} \mathrm{CD} 8^{+} \mathrm{T}$ cells; (c) the direct suppression of PD- 1 on PD- $1^{\text {hi }} \mathrm{CD} 8^{+} \mathrm{T}$ cells that become PD- $1^{\text {int }} \mathrm{CD} 8^{+} \mathrm{T}$ and $\mathrm{PD}-1^{-} \mathrm{CD} 8^{+} \mathrm{T}$ cells; and (d) the proliferation of $\mathrm{PD}-1^{\text {int }}$ and $\mathrm{PD}-1^{-} \mathrm{CD} 8^{+} \mathrm{T}$ cells.

To confirm whether the lower number of $\mathrm{PD}-\mathrm{h}^{\text {hi }} \mathrm{CD} 8^{+} \mathrm{T}$ cells is attributed to new infiltration, we used FTY720 to block newly activated T cells from leaving the draining lymph nodes during IL-21 treatment. $\mathrm{T}$ cells in PBMCs will become undetectable at 24 hours after 1 dose of FTY720 treatment. Our results showed that the FTY720 blockade did not affect the IL-21-induced MFI reduction of PD-1 in tumor-specific $\mathrm{CD}^{+} \mathrm{T}$ cells (Figure 5B). To investigate whether the PD-1 MFI reduction in $\mathrm{CD}^{+} \mathrm{T}$ cells is caused by the apoptosis of the PD-1 $1^{+} \mathrm{T}$ cell population, $\mathrm{CD} 8^{+} \mathrm{T}$ cells were sorted from C57B/L6 mouse spleens and activated by anti-CD3 and anti-CD28, with the addition of Erb-IL21, Erb, or neither. Very few apoptotic annexin $\mathrm{V}^{+} \mathrm{PD}-1^{+} \mathrm{CD} 8^{+} \mathrm{T}$ cells were observed, and there was no significant change in the number of apoptotic cells after treatment with Erb-IL21 or Erb (Supplemental Figure 8, A and B). We also analyzed apoptosis of PD- $1^{\text {hi }}$ and PD- $1^{\text {int }}$ antigen-specific CD8 ${ }^{+} \mathrm{T}$ cells in MC38-OVA tumors. Compared with the control group, there was no significant difference observed (Supplemental Figure 8C). These results suggest that the PD-1 reduction may not depend on IL-21-induced PD- $1^{+} \mathrm{CD} 8^{+} \mathrm{T}$ cell apoptosis. It has been reported that $\mathrm{PD}-1$ expression on $\mathrm{PD}-1^{+} \mathrm{CD} 8^{+} \mathrm{T}$ cells remains stable and $\mathrm{PD}-1^{+} \mathrm{CD} 8^{+} \mathrm{T}$ cells will not transform to $\mathrm{PD}-1^{-} \mathrm{CD} 8^{+} \mathrm{T}$ cells $(60-62)$. To determine whether $\mathrm{PD}-1$ expression on $\mathrm{PD}-1^{+} \mathrm{CD} 8^{+} \mathrm{T}$ cells also remains stable in our model, we tested the change of PD-1 expression on PD- $1^{+} \mathrm{CD} 8^{+} \mathrm{T}$ cells after IL- 21 treatment in vitro. Indeed, Erb-IL21 did not affect PD-1 expression and MFI on PD- $1^{+} \mathrm{CD} 8^{+} \mathrm{T}$ cells (Supplemental Figure 9, A and B). Together, these data suggest that the PD-1 reduction does not depend on the downregulation of PD-1 on PD- $1^{+} \mathrm{CD}^{+} \mathrm{T}$ cells

IL-21 selectively expands PD $1^{\text {int }}$ Tim- $3^{-} C D 8^{+}$functional $T$ cells in tumors. To investigate the cause of PD-1 MFI reduction in $\mathrm{CD}^{+} \mathrm{T}$ cells, we further tested the effect of IL-21 on the proliferation of PD- $1^{\text {int }}$ versus $\mathrm{PD}-1^{\text {hi }}$ populations among $\mathrm{CD}^{+} \mathrm{T}$ cells. We first analyzed the proliferation of $\mathrm{PD}-1^{\text {hi }}$ and $\mathrm{PD}-1^{\text {int }}$ populations using CSFE labeling in vitro. $\mathrm{CD}^{+} \mathrm{T}$ cells were activated by anti-CD3 and anti-CD28 in the presence of control or Erb-IL21 for 72 hours. Strikingly, IL-21 treatment led to increased proliferation of the PD-1 $1^{\text {int }}$ population compared with the $\mathrm{PD}-1^{\text {hi }}$ population among $\mathrm{CD}^{+} \mathrm{T}$ cells in vitro (Figure $5 \mathrm{C}$ ). To investigate the effect of IL-21 on the proliferation of the PD- $1^{\text {int }}$ versus PD- $1^{\text {hi }}$ population of tumor antigen-specific T cells, we intratumorally treated WT C57BL/6 mice bearing MC38-OVA tumors with IL-21 on day 12 and day 15 after tumor inoculation. PD- $1^{\text {int }}$ and $\mathrm{PD}-1^{\text {hi }}$ OVA-specific CD ${ }^{+} \mathrm{T}$ cells were isolated from tumor tissues 5 days after initial IL-21 treatment and stained with Ki-67 to identify proliferation by flow cytometry. Similarly, as in the in vitro setting, IL-21 preferentially induced the proliferation of PD $1^{\text {int }}$ rather than $\mathrm{PD} 1^{\text {hi }}$ OVA-specific $\mathrm{CD} 8^{+} \mathrm{T}$ cells in vivo (Figure $5 \mathrm{D}$ ). $\mathrm{PD}-1^{+} \mathrm{Tim}-3^{+} \mathrm{T}$ cells are highly dysfunctional compared with PD- $1^{+}$Tim- $3^{-}$and PD-1-Tim- $3^{-}$antigen-specific $\mathrm{CD} 8^{+} \mathrm{T}$ cells in tumors $(60,63)$. We further tested the frequency and number of $\mathrm{CD}^{+} \mathrm{T}$ cell subsets after IL-21 treatment, including PD-1-Tim-3PD $-1^{+}$Tim $-3^{-}$(PD-1 ${ }^{\text {int }}$ Tim $-3^{-}$and PD $-1^{\text {hi Tim }-3^{-}}$), and PD $-1^{+}$Tim $-3^{+}$cells. Specifically, we observed that the frequency of $\mathrm{PD}-1^{+}$Tim- $3^{+}$OVA-specific $\mathrm{CD} 8^{+} \mathrm{T}$ cells in tumors was reduced, and the frequency of $\mathrm{PD}-1^{\text {int- }}$ TIM3- OVA-specific CD8 ${ }^{+} \mathrm{T}$ cells was increased (Figure 5E). We also observed similar changes in $\mathrm{CD} 8^{+} \mathrm{T}$ cells (Figure 5, F and G). Moreover, the frequency of PD- $1^{\text {int }} \mathrm{Tim}-3^{-}$in $\mathrm{Ki}-67^{+} \mathrm{CD} 8^{+} \mathrm{T}$ cells was significantly increased after IL-21 treatment, while that of $\mathrm{PD}-1^{+} \mathrm{Tim}-3^{+}$in $\mathrm{Ki}-67^{+} \mathrm{CD} 8^{+} \mathrm{T}$ cells was reduced in tumors (Figure 5H). Together, these data suggest that IL-21 expands functional CTLs and restricts the development of exhausted $\mathrm{T}$ cells in the TME through selectively proliferating PD- $1^{\text {int }} \mathrm{Tim}-3^{-} \mathrm{CD} 8^{+} \mathrm{T}$ cells. Our study demonstrates that the targeted delivery of IL-21 expands a subset of antigen-specific CD8 ${ }^{+} \mathrm{T}$ cells and converts immune inhibition to tumor-killing activation in the TME.

IL-21 selectively increases proliferation of PD- $1^{\text {int }}$ Tim- $-3^{-} \mathrm{CD} 8^{+} \mathrm{T}$ cells while decreasing PD- $1^{+}$Tim$3^{+} \mathrm{CD}^{+} \mathrm{T}$ cells. To investigate whether PD- $1^{\text {int }} \mathrm{Tim}-3^{-} \mathrm{CD} 8^{+} \mathrm{T}$ cells contribute to the antitumor effect of IL-21, we sorted OVA-specific PD- $1^{\text {int }}$ Tim- $-3^{-} \mathrm{CD} 8^{+} \mathrm{T}$ cells and PD- $1^{+} \mathrm{Tim}-3^{+} \mathrm{CD} 8^{+} \mathrm{T}$ cells from MC38-OVA tumor after IL-21 treatment and did functional analysis. We examined the expression of IL-2, TNF- $\alpha$, and IFN- $\gamma$ in these cells by flow cytometry after coculture with OTI peptides and dendritic cells. PD- $1^{\text {int Tim }}$ ${ }^{-} \mathrm{CD} 8^{+} \mathrm{T}$ cells produced high levels of cytokines, while $\mathrm{PD}-1^{+} \mathrm{Tim}-3^{+} \mathrm{CD} 8^{+} \mathrm{T}$ cells almost had no cytokine 
A

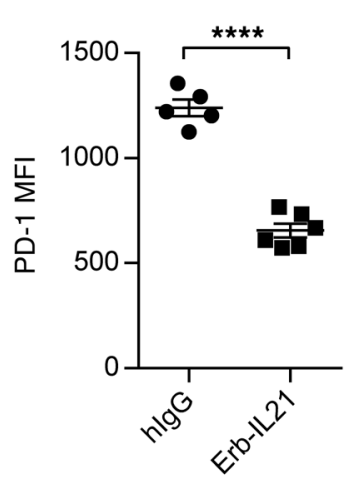

B

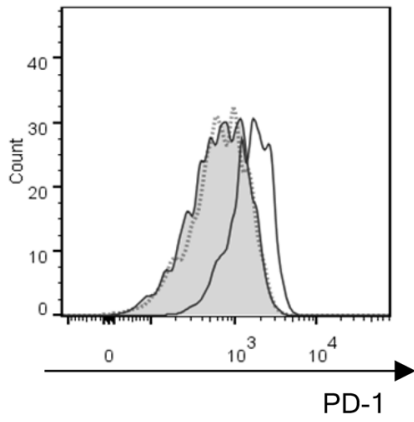

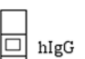

Erb-IL21

Erb-IL $21+$ FTY720
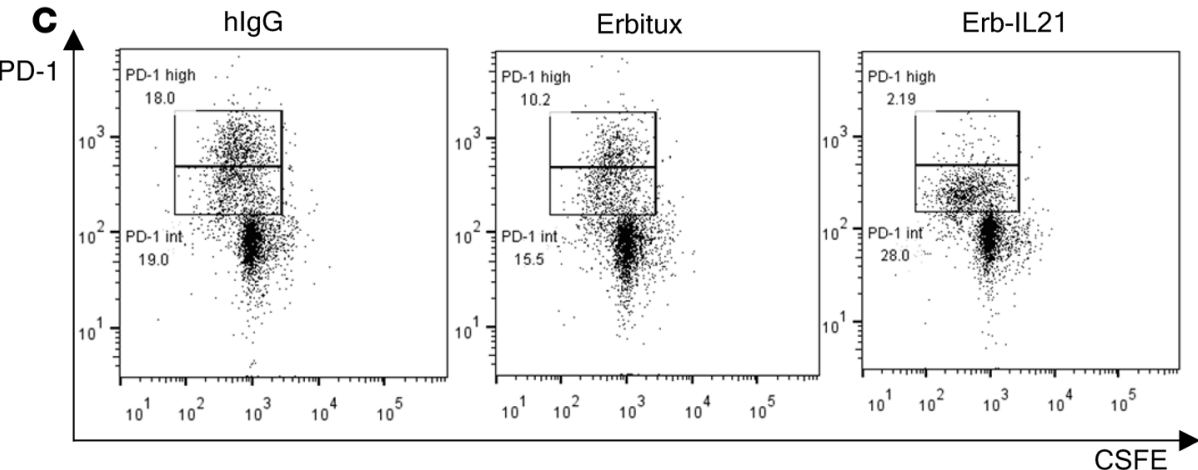
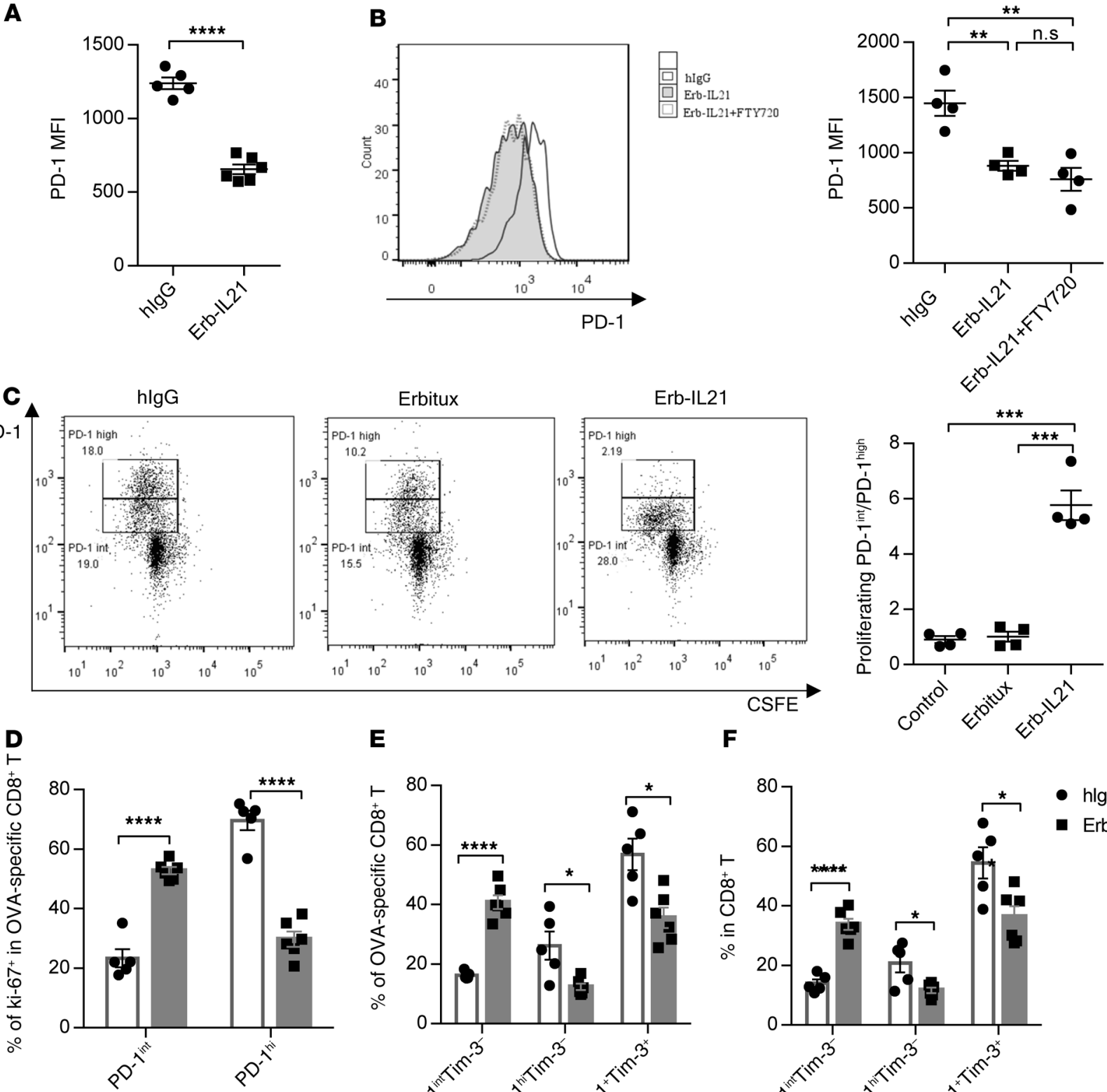

E

$\mathbf{F}$
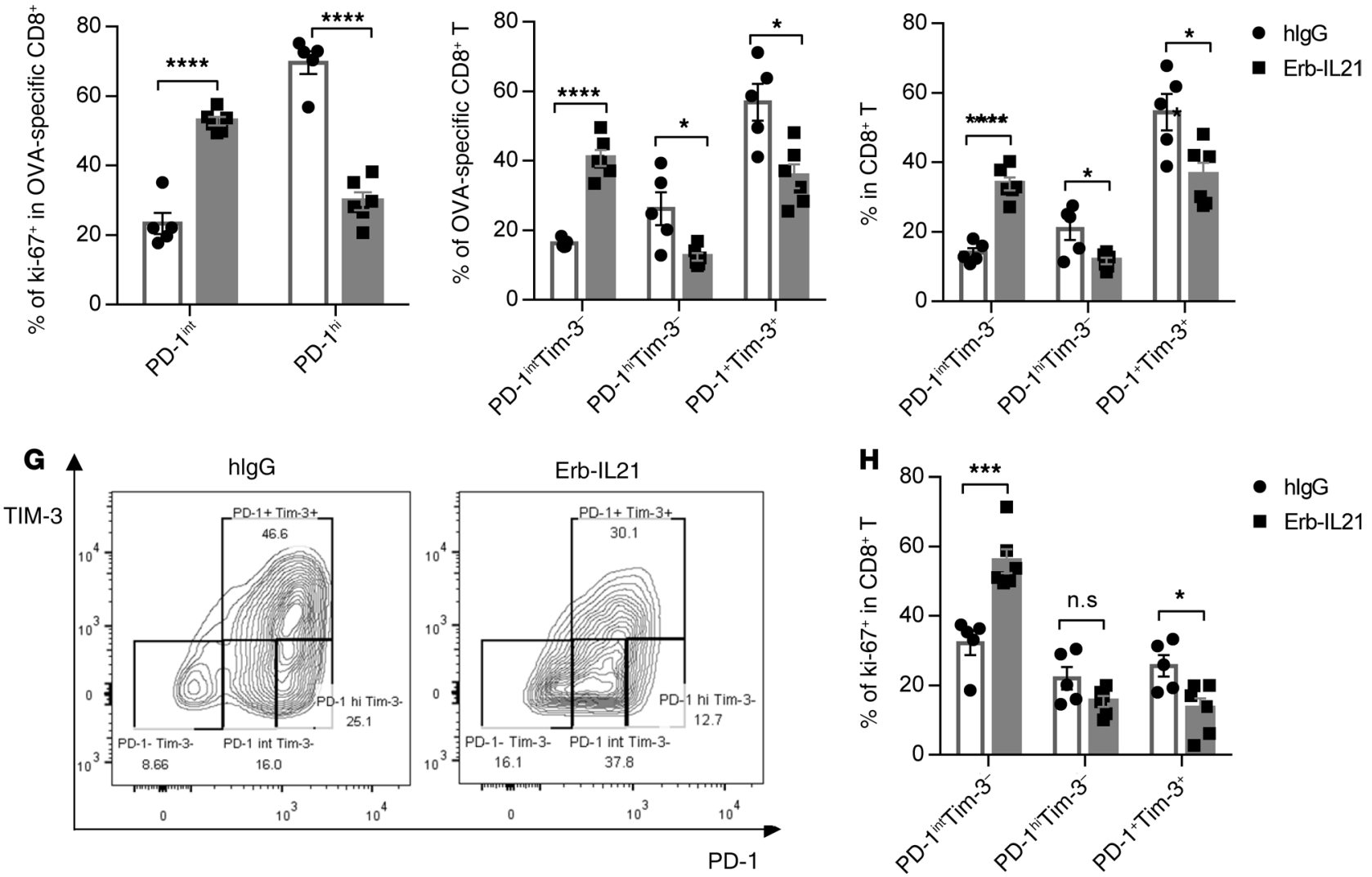

Figure 5. IL-21 proliferates PD-1 ${ }^{\text {int }}$ Tim-3- more than PD-1+Tim-3 +CD8 + $\mathbf{T}$ cells in tumors. (A, B, and E-G) C57BL/6 mice ( $\left.n=5-6\right)$ were inoculated with $6 \times 10^{5}$ to $8 \times 10^{5} \mathrm{MC} 38$-OVA cells and were intratumorally treated with $20 \mu \mathrm{g}$ hlgG or Erb-IL21 on days 12 and 15 . Five days after the first treatment, tumor tissues were analyzed by flow cytometry. (A) MFI of PD-1 on antigen-specific intratumoral CD8+ T cells. MFI is defined as the geometric median fluorescence intensity. (B) Tumor-bearing mice were i.p. treated with $25 \mu \mathrm{g}$ FTY720 1 day before treatment and every other day 3 times. MFI of PD-1 
on antigen-specific (OVA-specific) CD8 ${ }^{+}$T cells was analyzed. (C) The proliferation of PD-1+ $T$ cells. CFSE-labeled CD8 ${ }^{+}$T cells from C57BL/6 WT mouse spleen were cocultured with $0.2 \mu \mathrm{g}$ anti-CD3 and $0.2 \mu \mathrm{g}$ anti-CD28, with an additional $100 \mathrm{ng}$ Erbitux or Erb-IL21 for 72 hours. Cells treated with hlgC were used as control. The percentage of proliferating PD-1hi and PD-1int $C D 8^{+} T$ cells was analyzed by flow cytometry ( $n=3$ independent wells). (D) Fre-

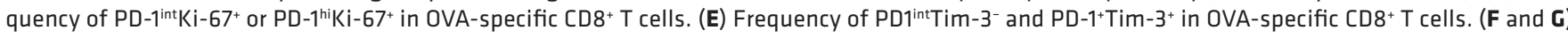

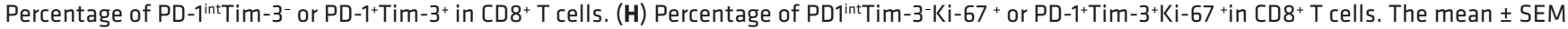
values are shown Unpaired $t$ tests were used to analyze the other data. ${ }^{*} P<0.05,{ }^{* *} P<0.01,{ }^{* *} P<0.0001,{ }^{* * *} P<0.0001$. One of two representative experiments is shown.

production (Figure 6, A-C). We also tested the protein level of TNF- $\alpha$ and IFN- $\gamma$ in the culture medium. The TNF- $\alpha$ and IFN- $\gamma$ levels produced by PD-1 ${ }^{\text {int }}$ Tim- $-3^{-} \mathrm{CD} 8^{+} \mathrm{T}$ cells were also much higher than those produced by $\mathrm{PD}-1^{+} \mathrm{Tim}-3^{+} \mathrm{CD} 8^{+} \mathrm{T}$ cells (Figure $6 \mathrm{D}$ ). These results suggest that $\mathrm{PD} 1^{\text {int }} \mathrm{Tim}-3^{-}$cells are more functional than PD- ${ }^{+} \mathrm{Tim}-3^{+} \mathrm{CD} 8^{+} \mathrm{T}$ cells in tumors. Collectively, our data indicate that the Erb-IL21 antitumor effect may depend on the function of PD- $1^{\text {int }}$ Tim- $-3^{-} \mathrm{CD} 8^{+} \mathrm{T}$ cells

Erb-IL21 synergizes with checkpoint blockade to control advanced tumors. In recent decades, antibodies targeting PD-1, Tim-3, and CTLA-4 inhibitory receptors have led to new effective immunotherapies for patients with advanced cancer (64-69). Although such therapies have shown additive effects in the clinic, 70\%-80\% of clinical patients are initially resistant to anti-PD-1 treatment, and more than half of the responsive patients eventually relapse (70). Many studies have attempted to explore potential combination therapies to overcome tumor resistance to ICBs (71).

Some TILs retain high levels of PD-1 expression. During Erb-IL21 treatment, we observed that PD-L1 expression is upregulated in DC cells and macrophages but not in tumor cells 7 days after the initial ErbIL21 treatment using the MC38-cEGFR tumor model (Supplemental Figure 10A). We speculated that blockade of the PD-1/PD-L1 axis could improve PD-1 ${ }^{+} \mathrm{T}$ cell function and that additional anti-PD-L1 therapy with Erb-IL21 can achieve amplified antitumor effects. To test this hypothesis, MC38-cEGFR tumor-bearing mice were treated with Erb-IL21 or anti-PD-L1 on day 14 when the tumors were well established. In tumor-bearing mice treated with the Erb-IL21 and anti-PD-L1 combination, we observed a significantly enhanced control of tumor growth compared with either single treatment (Figure 7A). Combined treatment of Erb-IL21 with anti-PD-L1 also extended the survival of mice (Figure 7B).

The depletion of Tregs can promote antitumor immunity (72). We measured the Treg abundance at different growth stages of MC38-cEGFR and observed that the number of Tregs in large tumors is much higher than that in small tumors (Supplemental Figure 10B). Consistent with the immunosuppressive function of Tregs in the TME, a single treatment with either Erb-IL21 or anti-CTLA-4 appeared to have little effect on the growth of these advanced tumors (Figure 7A). We proposed that tumor-targeted IL-21 could be effectively synergized with anti-CTLA-4 to reduce treatment resistance in large tumors. Indeed, the combination of Erb-IL21 with anti-CTLA-4 resulted in tumor clearance of all 7 mice treated (Figure 7A). Mouse survival was also enhanced after combined treatment by Erb-IL21 with anti-CTLA-4 (Figure 7B). Collectively, our data indicate that Erb-IL21 can synergize with ICB to control advanced tumors.

\section{Discussion}

IL-21 has been shown to exert potent antitumor activity against Mantle cell lymphoma via direct stimulation of NK cell-dependent lysis (73). IL -21 was also reported to be more effective than IL2 and IL-15 in controlling thymoma in the syngeneic mouse model through enhancing and sustaining $\mathrm{CD}^{+} \mathrm{T}$ cell responses (74). However, in clinical trials, IL-21 antitumor efficacy is limited by its short half-life. It has been shown that anti-CD20-IL21 and GIFT-21 can prolong the half-life of IL-21 and enhance the antitumor effect in non-Hodgkin lymphoma or melanoma tumor models $(1,2)$. In this study, we constructed a tumor-targeting fusion protein of IL-21 with FDA-approved Erb and prolonged the half-life of IL-21. Our results show that the targeted delivery of IL-21 enhanced the antitumor effect and reduced toxicity to undetectable levels, compared with the nontargeting control IL-21 fusion protein. The targeted delivery of IL-21 slowed tumor growth not only in colon cancer, but also in melanoma and fibroma tumor models, providing a potentially new approach for the treatment of a wide variety of cancers.

In our study, we used cEGFR-expressing tumors mainly to achieve an antibody-directed targeting of tumor; here, we provide a proof of concept indicating that tumor-targeted IL-21 enhances antitumor efficacy in mouse models. The Erb-IL21 fusion protein can target to human EGFR-derived cEGFR. To exclude the potential immunogenicity of human EGFR in mice, we also tested the Erb-IL21 antitumor effect in human EGFR-Tg mice (41) and observed that Erb-IL21 also inhibited tumor growth in EGFR-Tg mice. 
A

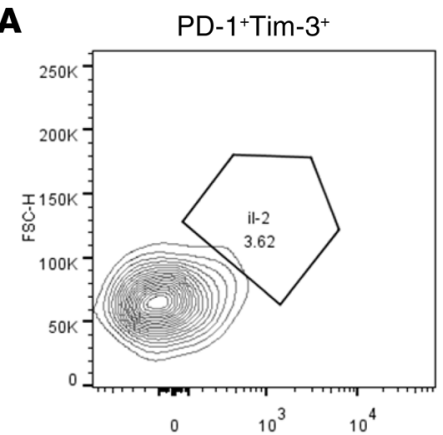

$\begin{array}{lll}0 & 10^{3} & 10^{4}\end{array}$

B

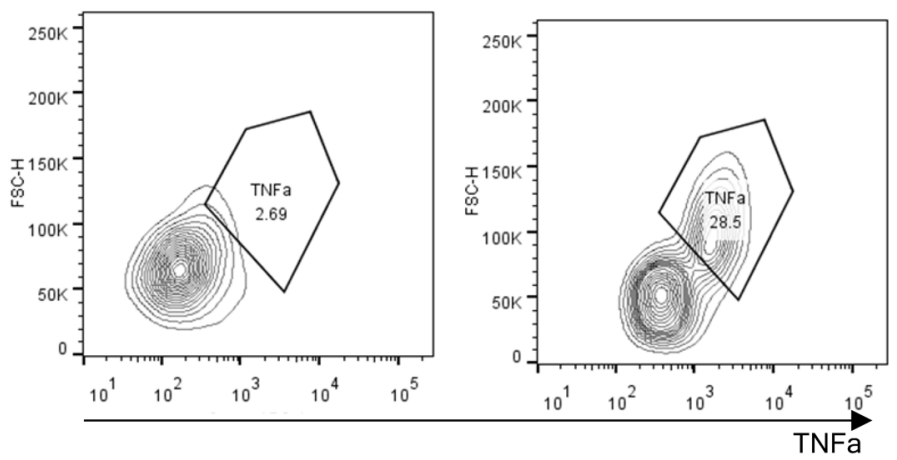

C
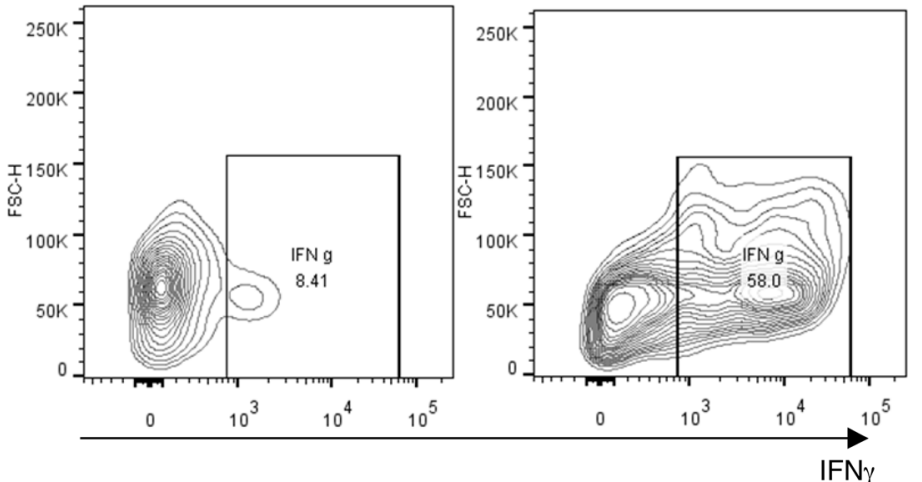

D

D $\quad \mathrm{TNF} \alpha$

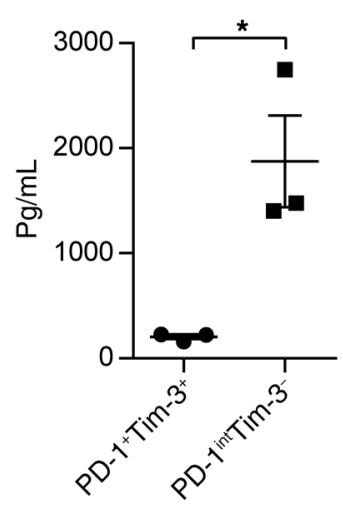

PD-1 ${ }^{\text {int Tim-3 }}$

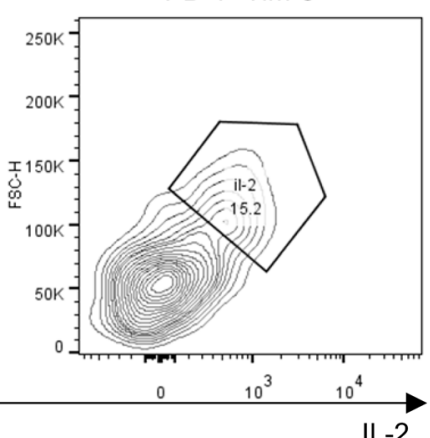

IL-2
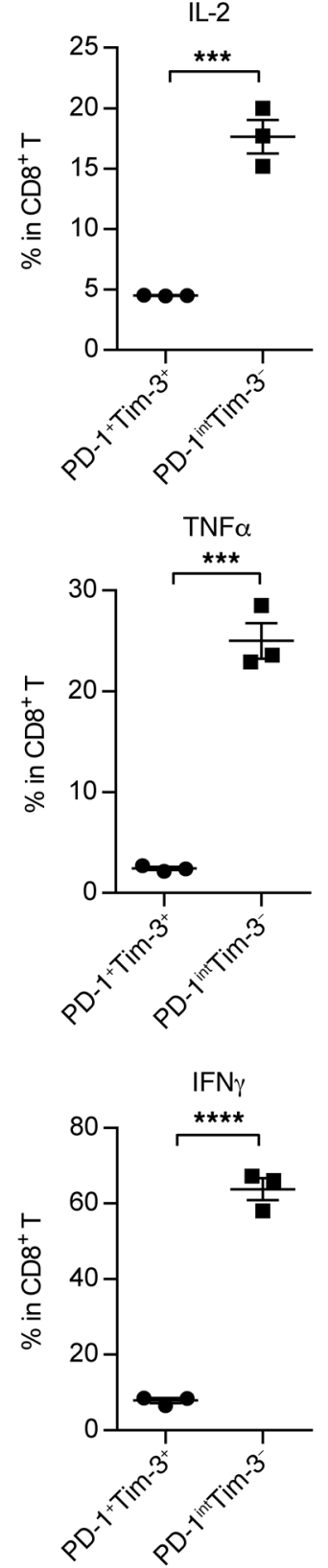

Figure 6. PD1 ${ }^{\text {int }}$ Tim-3- is more functional than PD-1+ Tim-3+ $\mathrm{CDB}^{+} \mathrm{T}$ cells in tumors. (A-C) OVA-specific CD8+ $T$ cells were sorted from MC38-OVA tumor and cocultured with bone marrow dendritic cells (BMDC) and SIINFEKL (OVA) peptides for 24 hours. Six hours before sacrifice, mice were i.v. treated with $250 \mu \mathrm{g}$ BFA. Frequency of IL-2-, TNF- $\alpha-$, and IFN- $\gamma$-producing cells was analyzed by flow cytometry ( $n=3$ independent wells). (D) TNF- $\alpha$ and IFN- $\gamma$ in the medium were measured using a CBA kit. The mean \pm SEM values are shown. Unpaired $t$ tests were used to analyze the other data. ${ }^{*} P<0.05$, ${ }^{* *} P<0.01$, ${ }^{* * *} P<0.0001,{ }^{* * * *} P<0.0001$. 
A

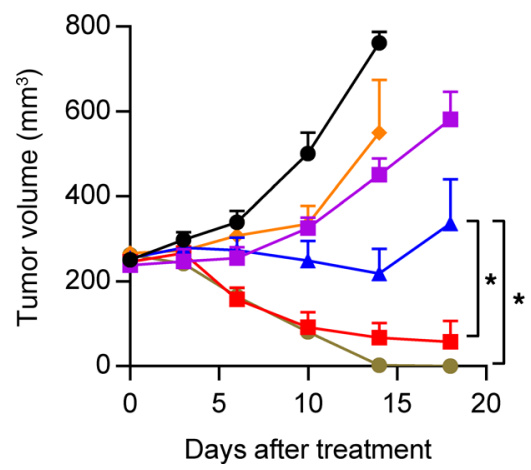

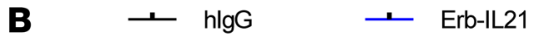

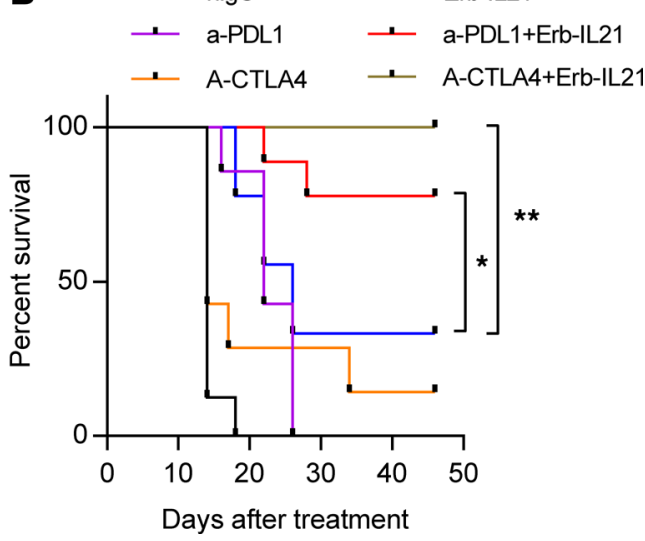

Figure 7. Synergy effect of Erb-IL21 with checkpoint blockade in advanced tumors. C57BL/6 mice $(n=7-9)$ were inoculated with $2.5 \times 10^{5}$ MC38-cEGFR cells and were i.p. treated with $75 \mu \mathrm{g}$ hlgG, $200 \mu \mathrm{g}$ anti-CTLA-4, $200 \mu \mathrm{g}$ anti-PD-L1, $75 \mu \mathrm{g}$ Erb-IL21, or combinations as indicated on days 14, 16, and 20. (A) Tumor growth was measured twice weekly. (B) Survival curve. The mean \pm SEM values are shown. Two-way ANOVA tests were used to analyze the tumor growth data. ${ }^{*} P<0.05,{ }^{* *} P<0.01$. One of two representative experiments is shown.

Thus, tumor-targeting IL-21 will be of more benefit to patients with high levels of tumor-associated antigens on the surface of tumor cells, such as CLDN18.2, EGFRVIII, or Her/2.

As the first cytokine approved by the FDA, IL-2 has been widely used in combination treatment in the clinic to promote the function of $\mathrm{CD} 8^{+} \mathrm{T}$ cells. However, IL-2 also stimulates Tregs, which exert an immunosuppressive function in the TME, and IL-2 is too toxic for almost all patients (75-77). In contrast, IL-21 not only recalls $\mathrm{CD} 8^{+} \mathrm{T}$ cell-mediated antitumor responses by enhancing the effector and memory functions of $\mathrm{CD} 8^{+} \mathrm{T}$ cells, but it also suppresses the function of Tregs (20-24). Compared with IL-2, our tumor-targeting Erb-IL21 presents potent antitumor efficacies, along with significantly less toxicity.

Dysfunctional CTLs have a loss of effector function and proliferative potential, along with expression of inhibitory markers, such as PD-1, Tim-3, and CTLA-4 $(78,79)$. The reinvigoration of the immune response by ICB to interfere with PD-1 or other inhibitory pathways provided a complementary approach for antitumor therapies $(80,81)$. PD $-1^{+}$Tim $-3^{+}$CTLs correlate with more severe dysfunction than PD-1 ${ }^{+}$Tim-3- $3^{-}$and PD-1-Tim-3- CTLs $(63,82)$. Recent studies have shown that maintaining $\mathrm{CD} 8^{+} \mathrm{T}$ cells in a self-renewed state could enhance persistence and antitumor function $(83,84)$. However, ICB has mainly removed the brake and might have a limited effect on the rapid expansion of functional TILs. Providing T cell growth factors might more directly expand TILs. We found that IL-21 resulted in a significant reduction of the PD-1 level on $\mathrm{CD} 8^{+} \mathrm{T}$ cells in the tumor. This reduction was independent of new $\mathrm{CD} 8^{+} \mathrm{T}$ cell infiltration, or $\mathrm{PD}-1^{+} \mathrm{CD} 8^{+} \mathrm{T}$ cell apoptosis, or downregulation of $\mathrm{PD}-1$ expression on $\mathrm{PD}-1^{+} \mathrm{CD} 8^{+} \mathrm{T}$ cells but depended on selective proliferation of $\mathrm{PD}-1^{\text {int }} \mathrm{Tim}-3^{-} \mathrm{CD} 8^{+} \mathrm{T}$ cells. Our study demonstrates that tumor-targeting IL-21 can increase antigen-specific CD $8^{+} \mathrm{T}$ function and proliferation, especially in the PD- ${ }^{\text {int }}$ Tim- $3^{-}$population. Furthermore, tumor-targeting IL-21 can assist $\mathrm{CD} 8^{+} \mathrm{T}$ cells in sustaining their self-renewal abilities and reducing the frequency of PD-1+TIM-3 ${ }^{+}$ antigen-specific $\mathrm{CD} 8^{+} \mathrm{T}$ cells in tumors.

Checkpoint blockades releasing the brakes of host immune responses have achieved remarkable progress in $10 \%-20 \%$ of patients with cancer $(72,85)$. Therapies with cytokines have also contributed to the long-term tumor control in a small fraction of patients $(86,87)$ and showed enhanced clinical efficacy $(88$ 91). Our results showed that, even in large tumors resistant to checkpoint blockade with exhausted CTLs, the systemic administration of Erb-IL21 in combination with anti-PD-L1 and anti-CTLA-4 achieved significant antitumor effects and extended survival. The PD-1/PD-L1 axis and anti-CTLA-4 mediate antitumor effects in distinct ways. The PD-1/PD-L1 axis regulates the immune response in tumors, while anti-CTLA-4 primarily regulates the immune response in lymph nodes (72). Although Erb-IL21 antitumor function depends on preexisting TILs in tumors, anti-CTLA-4 combined with Erb-IL21 may invoke T cell responses in both lymph nodes and tumors. This synergistic effect will significantly improve therapeutic efficacy, even in advanced tumors resistant to multiple therapies. 
In summary, our results define a crucial role for IL-21 in fighting tumors by promoting the proliferation of $\mathrm{PD}-1^{\mathrm{int}} \mathrm{Tim}-3^{-} \mathrm{CD} 8^{+} \mathrm{T}$ cells and reducing the frequency of dysfunctional $\mathrm{PD}-1^{+} \mathrm{Tim}-3^{+}$tumor antigen-specific $\mathrm{CD}^{+} \mathrm{T}$ cells in TEMs. Our data demonstrate that Erb-IL21 therapy, in combination with checkpoint blockades, reinvigorates antitumor immune responses and is a neoadjuvant treatment option.

\section{Methods}

Mice. Six- to eight-week-old female C57BL/6 WT mice and B6C3F1 mice were purchased from Vital River Laboratories. Tet-on EGFR-Tg mice were provided by Harold Varmus at the National Cancer Institute, Bethesda, Maryland, USA. These mice were crossed with B6 mice for up to 10 generations. All mice were maintained under specific pathogen-free conditions, and animal protocols were consistent with the NIH guidelines.

Cell lines and reagents. B16-cEGFR, MC38-cEGFR, and Ag104Ld-cEGFR were selected from a single clone after being transduced by lentivirus. MC38 and MC38-OVA were cultured in 5\% $\mathrm{CO}_{2}$ and maintained in vitro in Dulbecco's modified Eagle's medium (Corning), supplemented with $10 \%$ heat-inactivated fetal bovine, $2 \mathrm{mmol} / \mathrm{L}$ glutamine, $0.1 \mathrm{mmol} / \mathrm{L}$ Minimum Essential Medium nonessential amino acids, $100 \mathrm{U} / \mathrm{ml}$ penicillin, and $100 \mathrm{mg} / \mathrm{ml}$ streptomycin. The following antibodies were used in this study: anti-mouse CD4 (BioXcell, BE0003-1), anti-mouse CD8 (BioXcell, BE0117), anti-mouse NK1.1 (BioXcell, BE0036), antimouse PD-L1 (BioXcell, BE0101), anti-mouse CSF1R (BioXcell, BE0213), anti-mouse CD45 (Invitrogen, 56-0451-82), anti-mouse CD4 (Invitrogen, 45-0042-82), anti-mouse CD152 (UC10-4B9, Invitrogen, 17-152282), anti-Foxp3 (Invitrogen, 12-5773), anti-mouse CD3ع (Invitrogen, 48-0032-80), anti-mouse CD11b (Invitrogen, 45-0112), LIVE/DEAD (Invitrogen, L34959), anti-mouse Ki-67(BioLegend, 652413), anti-mouse CD279 (BioLegend, 135231), anti-mouse CD366(BioLegend, 119715), anti-mouse CD8 (Biolegend, 100714), and anti-mouse F4/80 (Biolegend, 123113). Erb (Cetuximab) was purchased from Merck Lipha. Fc $\gamma$ RII/III blocking antibody (2.4G2) was produced in-house. The following reagents were used in this study: annexin V (BioLegend, 640912), 7-AAD Viability Staining Solution (BioLegend, 420404), and iTAg Tetramer/PE-H-2 Kb OVA (SIINFEKL, MBL, TB-5001-1). FTY720 (hydrochloride) was purchased from MilliporeSigma.

Tumor challenge and treatment. Approximately $2.5 \times 10^{5}$ to $5 \times 10^{5}$ of MC38, MC38-cEGFR, B16-cEGFR, and Ag104Ld-cEGFR cells were injected subcutaneously in the right flank of 6- to 8-week-old mice. For the double-tumor model, $0.5 \times 10^{5} \mathrm{MC} 38$ and $1.5 \times 10^{5} \mathrm{MC} 38$-cEGFR cells were injected subcutaneously in the left and right flanks of 6- to 8-week-old C57BL/6 mice, respectively. Tumor volumes were measured twice a week, and volume was calculated (length $\times$ width $\times$ height $/ 2$ ). After the tumor was established, the mice were treated with intratumoral injections of $20 \mu \mathrm{g}$ ERB-IL21 or control antibody every other day 3 or 4 times in some experiments. For systemic treatment, tumor-bearing mice were i.p. injected with $75 \mu \mathrm{g}$ Erb-IL21 or control antibody 3 times within a week. To block lymphocyte trafficking, we i.p. injected the mice with $25 \mu \mathrm{g}$ FTY720 1 day before Erb-IL21 treatment and then every other day 4 times to maintain the blockade. For depletion of different types of cells, a $200 \mu \mathrm{g}$ dose of anti-CD8 (clone TIB210) or anti-CD4 (GK1.5) was injected i.p. 1 day before antibody treatment; every 3 days after that anti-NK1.1 was injected i.p. at a dose of $400 \mu \mathrm{g} 1$ day before Erb-IL21 treatment and every 4 days after that. AntiCFS1R was injected i.p. at a dose of $300 \mu \mathrm{g} 1$ day before Erb-IL21 treatment and every 3 days after that. For combination treatment, tumor-bearing mice were i.p. treated with a single therapy of $75 \mu \mathrm{g}$ hIgG, 200 $\mu \mathrm{g}$ anti-CTLA-4, $200 \mu \mathrm{g}$ anti-PD-L1, $75 \mu \mathrm{g}$ Erb-IL21, or combination treatment on days 15, 18, and 21.

Flow cytometry analysis. Tumor tissues were removed from mice and digested in DMEM supplemented with $2 \%$ fetal serum and $0.1 \%$ collagenase for 30 minutes at $37^{\circ} \mathrm{C}$, followed by being washed and passed through a 40-mm cell strainer. After centrifugation, a single-cell suspension in FACS buffer supplemented with $2 \%$ bovine serum albumin and $0.05 \% \mathrm{NaN}_{3}$ was blocked with anti-CD16/32 (anti-Fc $\gamma \mathrm{III} /$ II receptor, clone 2.4G2) for 15 minutes and incubated with the indicated antibodies for 30 minutes at $4^{\circ} \mathrm{C}$. For flow cytometry analysis, the cells were acquired from a FACS Caliber (BD Biosciences), and the data were analyzed with FlowJo software. For IFN- $\gamma$ staining, mice were i.v. injected with $250 \mu \mathrm{g}$ BFA 6 hours before sacrifice to enhance intracellular cytokine staining signals by blocking transport processes during cell activation.

Ex vivo binding assay. A single-cell suspension of MC38-cEGFR $\left(1 \times 10^{6}\right.$ cells $)$ was prepared by incubation with Erb-IL21 or LA22-IL21 for 30 minutes at $4^{\circ} \mathrm{C}$. The cells were washed 5 times and then stained with anti-mouse IL21-APC for half an hour. After washing 3 times, the samples were analyzed on a FACS Fortessa flow cytometer (BD). The data were analyzed using FlowJo software (TreeStar).

Fluorescence imaging. C57BL/6 mice were inoculated s.c. with MC38 tumor cells into the left flank and MC38-cEGFR tumor cells into the right flank. Then, these double-tumor-bearing mice were treated with 
Cy5.5-labeled Erb-IL21 or LA22-IL21. Fluorescently labeled Erb-IL21 or LA22-IL21 (75 $\mu \mathrm{g})$ was injected i.v. into C57BL/6 mice bearing subcutaneous MC38 (left flank) and MC38-cEGFR (right flank) tumors. Fluorescence was measured with IVIS Spectrum at the indicated time points.

Statistics. "Data are shown as the mean \pm SEM. Statistical analyses were performed using a 2-tailed unpaired Student's $t$ test Tumor growth after different treatments was analyzed by 2-way ANOVA. The survival curves were generated by the Kaplan-Meier method and compared with the Gehan-Wilcoxon test. A 2-tailed Mann-Whitney test was used to assess significant differences between experimental groups. A $P$ value of less than 0.05 was considered statistically significant. All statistical analyses were performed using GraphPad Prism software 5.0.

Study approval. Protocols for animal experiments were consistent with NIH guidelines. All studies were approved by the Animal Care and Use Committee of the Institute of Biophysics, Chinese Academy of Sciences.

\section{Author contributions}

SD, HP, and YXF conceived and designed the study. SD developed methodology. SD, ZS, JQ, YL, LL, $\mathrm{CD}, \mathrm{AS}$, and YW acquired data. SD, YXF, and HP analyzed and interpreted data (e.g., statistical analysis, biostatistics, computational analysis). SD, YL, HP, and YXF wrote, reviewed, and revised the manuscript. ZS, YL, HP, and YXF provided administrative, technical, or material support (i.e., reporting or organizing data and constructing databases). HT, HP, and YXF provided study supervision.

\section{Acknowledgments}

We thank Casey Moore for reviewing the manuscript. We thank Haidong Tang, Meng Xu, Zhida Liu, Xuezhi Cao, Yang Pu, Changzheng Lu, Zhenhua Ren, and Chuanhui Han for technical assistance. We thank Ximei Zhang, Yanfei Han, Shuaishuai Cao, Hairong Xu, Kaiting Yang, and Jingya Guo for technical assistance in the Institute of Biophysics. This work was supported by funding from the Chinese Academy of Sciences (KFJ-STS-ZDTP-062, 153831KYSB20160038, and XDA12020212 to HP).

Address correspondence to: Hong Tang, Institute Pasteur of Shanghai, Chinese Academy of Sciences, 320 Yue-yang Road, Shanghai 200031, China. Phone: 8621.5492.3001; Email: htang@ips.ac.cn. Or to: YangXin Fu, Department of Pathology, University of Texas Southwestern Medical Center, 6000 Harry Hines Boulevard, Dallas, Texas 75235, USA. Phone: 773.307.5478; Email: yang-xin.fu@utsouthwestern.edu. Or to: Hua Peng, Key Laboratory of Infection and Immunity, Institute of Biophysics, Chinese Academy of Sciences, Datun Road, Beijing 100101, China. Phone: 8610.6488.1152; Email: hpeng@moon.ibp.ac.cn.

1. Gajewski TF, Schreiber H, Fu YX. Innate and adaptive immune cells in the tumor microenvironment. Nat Immunol. 2013;14(10):1014-1022.

2. Galon J, Bruni D. Approaches to treat immune hot, altered and cold tumours with combination immunotherapies. Nat Rev Drug Discov. 2019;18(3):197-218.

3. Spranger S, Gajewski TF. Impact of oncogenic pathways on evasion of antitumour immune responses. Nat Rev Cancer. 2018;18(3):139-147

4. Jie HB, Srivastava RM, Argiris A, Bauman JE, Kane LP, Ferris RL. Increased PD-1+ and TIM- $3^{+}$TILs during cetuximab therapy inversely correlate with response in head and neck cancer patients. Cancer Immunol Res. 2017;5(5):408-416.

5. Fucikova J, et al. TIM-3 dictates functional orientation of the immune infiltrate in ovarian cancer. Clin Cancer Res. 2019;25(15):4820-4831.

6. Ma J, et al. $\mathrm{PD} 1^{\mathrm{Hi}} \mathrm{CD}^{+} \mathrm{T}$ cells correlate with exhausted signature and poor clinical outcome in hepatocellular carcinoma. J Immunother Cancer. 2019;7(1):331.

7. Vidard L, et al. CD137 (4-1BB) engagement fine-tunes synergistic IL-15- and IL-21-driven NK cell proliferation. J Immunol. 2019;203(3):676-685

8. Burrack KS, et al. Interleukin-15 complex treatment protects mice from cerebral malaria by inducing interleukin-10-producing natural killer cells. Immunity. 2018;48(4):760-772.e4.

9. Ni J, Miller M, Stojanovic A, Garbi N, Cerwenka A. Sustained effector function of IL-12/15/18-preactivated NK cells against established tumors. J Exp Med. 2012;209(13):2351-2365.

10. Coquet JM, et al. IL-21 is produced by NKT cells and modulates NKT cell activation and cytokine production. J Immunol. 2007;178(5):2827-2834.

11. Coquet JM, et al. Interleukin-21-producing CD4(+) T cells promote type 2 immunity to house dust mites. Immunity. 2015;43(2):318-330

12. Dillman RO, Wiemann MC, VanderMolen LA, Bury MJ, DePriest C, Church C. Hybrid high-dose bolus/continuous infusion interleukin-2 in patients with metastatic melanoma: a phase II trial of the Cancer Biotherapy Research Group (formerly the National Biotherapy Study Group). Cancer Biother Radiopharm. 1997;12(4):249-255. 
13. Wood R, Montoya JG, Kundu SK, Schwartz DH, Merigan TC. Safety and efficacy of polyethylene glycol-modified interleukin-2 and zidovudine in human immunodeficiency virus type 1 infection: a phase I/II study. J Infect Dis. 1993;167(3):519-525.

14. Pérez-Martínez A, et al. A phase I/II trial of interleukin-15--stimulated natural killer cell infusion after haplo-identical stem cell transplantation for pediatric refractory solid tumors. Cytotherapy. 2015;17(11):1594-1603.

15. Schmidt H, et al. Safety and clinical effect of subcutaneous human interleukin-21 in patients with metastatic melanoma or renal cell carcinoma: a phase I trial. Clin Cancer Res. 2010;16(21):5312-5319.

16. Steele N, et al. A phase 1 trial of recombinant human IL-21 in combination with cetuximab in patients with metastatic colorectal cancer. Br J Cancer. 2012;106(5):793-798.

17. Davis ID, et al. An open-label, two-arm, phase I trial of recombinant human interleukin-21 in patients with metastatic melanoma. Clin Cancer Res. 2007;13(12):3630-3636.

18. Leonard WJ, Spolski R. Interleukin-21: a modulator of lymphoid proliferation, apoptosis and differentiation. Nat Rev Immunol. 2005;5(9):688-698.

19. Parrish-Novak J, et al. Interleukin 21 and its receptor are involved in NK cell expansion and regulation of lymphocyte function. Nature. 2000;408(6808):57-63

20. Zeng R, et al. Synergy of IL-21 and IL-15 in regulating CD8+ T cell expansion and function. J Exp Med. 2005;201(1):139-148.

21. Tian Y, Cox MA, Kahan SM, Ingram JT, Bakshi RK, Zajac AJ. A context-dependent role for il-21 in modulating the differentiation, distribution, and abundance of effector and memory CD8 T cell subsets. J Immunol. 2016;196(5):2153-2166.

22. Allard EL, et al. Overexpression of IL-21 promotes massive CD8+ memory T cell accumulation. Eur J Immunol. 2007;37(11):3069-3077.

23. Spolski R, Leonard WJ. Interleukin-21: basic biology and implications for cancer and autoimmunity. Annu Rev Immunol. 2008;26:57-79.

24. Ozaki K, Kikly K, Michalovich D, Young PR, Leonard WJ. Cloning of a type I cytokine receptor most related to the IL-2 receptor beta chain. Proc Natl Acad Sci USA. 2000;97(21):11439-11444.

25. Fantini MC, et al. IL-21 regulates experimental colitis by modulating the balance between Treg and Th17 cells. Eur J Immunol. 2007;37(11):3155-3163.

26. Yi JS, Cox MA, Zajac AJ. T-cell exhaustion: characteristics, causes and conversion. Immunology. 2010;129(4):474-481.

27. Welsh RM. Assessing CD8 T cell number and dysfunction in the presence of antigen. J Exp Med. 2001;193(5):F19-F22.

28. Wherry EJ. T cell exhaustion. Nat Immunol. 2011;12(6):492-499.

29. Pauken KE, Wherry EJ. Overcoming T cell exhaustion in infection and cancer. Trends Immunol. 2015;36(4):265-276.

30. Nguyen LT, Ohashi PS. Clinical blockade of PD1 and LAG3--potential mechanisms of action. Nat Rev Immunol. $2015 ; 15(1): 45-56$

31. Brahmer JR, et al. Safety and activity of anti-PD-L1 antibody in patients with advanced cancer. $N$ Engl J Med. 2012;366(26):2455-2465.

32. Phan GQ, Weber JS, Sondak VK. CTLA-4 blockade with monoclonal antibodies in patients with metastatic cancer: surgical issues. Ann Surg Oncol. 2008;15(11):3014-3021.

33. Phan GQ, et al. Cancer regression and autoimmunity induced by cytotoxic T lymphocyte-associated antigen 4 blockade in patients with metastatic melanoma. Proc Natl Acad Sci USA. 2003;100(14):8372-8377.

34. Omar HA, Tolba MF. Tackling molecular targets beyond PD-1/PD-L1: Novel approaches to boost patients' response to cancer immunotherapy. Crit Rev Oncol Hematol. 2019;135:21-29.

35. Wang Q, Wu X. Primary and acquired resistance to PD-1/PD-L1 blockade in cancer treatment. Int Immunopharmacol. 2017;46:210-219

36. Yi JS, Du M, Zajac AJ. A vital role for interleukin-21 in the control of a chronic viral infection. Science. 2009;324(5934):1572-1576

37. Xu M, et al. Intratumoral delivery of IL-21 overcomes anti-Her2/Neu resistance through shifting tumor-associated macrophages from M2 to M1 phenotype. J Immunol. 2015;194(10):4997-5006.

38. Bhatt S, et al. Anti-CD20-interleukin-21 fusokine targets malignant B cells via direct apoptosis and NK-cell-dependent cytotoxicity. Blood. 2017;129(16):2246-2256.

39. Qiao J, et al. Targeting tumors with il-10 prevents dendritic cell-mediated CD8+ T cell apoptosis. Cancer Cell. 2019;35(6):901-915.e4.

40. Sun Z, et al. A next-generation tumor-targeting IL-2 preferentially promotes tumor-infiltrating CD8 ${ }^{+} \mathrm{T}$-cell response and effective tumor control. Nat Commun. 2019;10(1):3874.

41. Politi K, Zakowski MF, Fan PD, Schonfeld EA, Pao W, Varmus HE. Lung adenocarcinomas induced in mice by mutant EGF receptors found in human lung cancers respond to a tyrosine kinase inhibitor or to down-regulation of the receptors. Genes Dev. 2006;20(11):1496-1510.

42. Peluso I, et al. IL-21 counteracts the regulatory T cell-mediated suppression of human CD4+ T lymphocytes. J Immunol. 2007;178(2):732-739.

43. Mittal D, et al. Improved treatment of breast cancer with anti-HER2 therapy requires interleukin-21 signaling in CD8+ T cells Cancer Res. 2016;76(2):264-274.

44. Li Y, Yee C. IL-21 mediated Foxp3 suppression leads to enhanced generation of antigen-specific CD8+ cytotoxic T lymphocytes. Blood. 2008;111(1):229-235.

45. Ahmadzadeh M, Rosenberg SA. IL-2 administration increases CD4+ CD25(hi) Foxp3+ regulatory T cells in cancer patients. Blood. 2006;107(6):2409-2414.

46. Cesana GC, et al. Characterization of CD4+CD25+ regulatory T cells in patients treated with high-dose interleukin-2 for metastatic melanoma or renal cell carcinoma. J Clin Oncol. 2006;24(7):1169-1177.

47. Wei S, et al. Interleukin-2 administration alters the CD4+FOXP3+ T-cell pool and tumor trafficking in patients with ovarian carcinoma. Cancer Res. 2007;67(15):7487-7494.

48. Skrombolas D, Frelinger JG. Challenges and developing solutions for increasing the benefits of IL-2 treatment in tumor therapy. Expert Rev Clin Immunol. 2014;10(2):207-217.

49. Panelli MC, et al. Forecasting the cytokine storm following systemic interleukin (IL)-2 administration. J Transl Med. 2004;2(1):17. 
50. Abbas AK, Trotta E, R Simeonov D, Marson A, Bluestone JA. Revisiting IL-2: Biology and therapeutic prospects. Sci Immunol. 2018;3(25):eaat1482.

51. Kasaian MT, et al. IL-21 limits NK cell responses and promotes antigen-specific T cell activation: a mediator of the transition from innate to adaptive immunity. Immunity. 2002;16(4):559-569.

52. Seo H, et al. IL21 therapy combined with PD-1 and Tim-3 blockade provides enhanced NK cell antitumor activity against MHC class I-deficient tumors. Cancer Immunol Res. 2018;6(6):685-695.

53. Li Y, Bleakley M, Yee C. IL-21 influences the frequency, phenotype, and affinity of the antigen-specific CD8 T cell response. J Immunol. 2005;175(4):2261-2269.

54. Thompson ED, Enriquez HL, Fu YX, Engelhard VH. Tumor masses support naive T cell infiltration, activation, and differentiation into effectors. J Exp Med. 2010;207(8):1791-1804.

55. Kastirr I, et al. IL-21 is a central memory T cell-associated cytokine that inhibits the generation of pathogenic Th1/17 effector cells. J Immunol. 2014;193(7):3322-3331.

56. Seo H, et al. IL-21-mediated reversal of NK cell exhaustion facilitates anti-tumour immunity in MHC class I-deficient tumours. Nat Commun. 2017;8:15776.

57. Wherry EJ, et al. Molecular signature of CD8+ T cell exhaustion during chronic viral infection. Immunity. 2007;27(4):670-684.

58. Kansy BA, et al. PD-1 status in CD8 ${ }^{+} \mathrm{T}$ cells associates with survival and anti-PD-1 therapeutic outcomes in head and neck cancer. Cancer Res. 2017;77(22):6353-6364.

59. Myklebust JH, et al. High PD-1 expression and suppressed cytokine signaling distinguish T cells infiltrating follicular lymphoma tumors from peripheral T cells. Blood. 2013;121(8):1367-1376.

60. Kurtulus S, et al. Checkpoint blockade immunotherapy induces dynamic changes in $\mathrm{PD}-1^{-} \mathrm{CD} 8^{+}$tumor-infiltrating $\mathrm{T}$ cells. Immunity. 2019;50(1):181-194.e6.

61. Utzschneider DT, et al. T cells maintain an exhausted phenotype after antigen withdrawal and population reexpansion. Nat Immunol. 2013;14(6):603-610.

62. Ahn E, Youngblood B, Lee J, Lee J, Sarkar S, Ahmed R. Demethylation of the PD-1 Promoter Is Imprinted during the Effector Phase of CD8 T Cell Exhaustion. J Virol. 2016;90(19):8934-8946.

63. Fourcade J, et al. Upregulation of Tim-3 and PD-1 expression is associated with tumor antigen-specific CD8+ T cell dysfunction in melanoma patients. J Exp Med. 2010;207(10):2175-2186.

64. Powles T, et al. MPDL3280A (anti-PD-L1) treatment leads to clinical activity in metastatic bladder cancer. Nature. 2014;515(7528):558-562.

65. Afanasiev OK, et al. Merkel polyomavirus-specific T cells fluctuate with merkel cell carcinoma burden and express therapeutically targetable PD-1 and Tim-3 exhaustion markers. Clin Cancer Res. 2013;19(19):5351-5360.

66. Rizvi NA, et al. Activity and safety of nivolumab, an anti-PD-1 immune checkpoint inhibitor, for patients with advanced, refractory squamous non-small-cell lung cancer (CheckMate 063): a phase 2, single-arm trial. Lancet Oncol. 2015;16(3):257-265.

67. Lee PP, et al. Characterization of circulating T cells specific for tumor-associated antigens in melanoma patients. Nat Med 1999;5(6):677-685.

68. Zou W, Wolchok JD, Chen L. PD-L1 (B7-H1) and PD-1 pathway blockade for cancer therapy: Mechanisms, response biomarkers, and combinations. Sci Transl Med. 2016;8(328):328rv4.

69. Ferris RL, et al. Nivolumab in patients with recurrent or metastatic squamous cell carcinoma of the head and neck: efficacy and safety in CheckMate 141 by prior cetuximab use. Clin Cancer Res. 2019;25(17):5221-5230.

70. O’Donnell JS, Long GV, Scolyer RA, Teng MW, Smyth MJ. Resistance to PD1/PDL1 checkpoint inhibition. Cancer Treat Rev. 2017;52:71-81.

71. Sharma P, Hu-Lieskovan S, Wargo JA, Ribas A. Primary, adaptive, and acquired resistance to cancer immunotherapy. Cell. 2017;168(4):707-723

72. Buchbinder EI, Desai A. CTLA-4 and PD-1 pathways: similarities, differences, and implications of their inhibition. Am JClin Oncol. 2016;39(1):98-106.

73. Bhatt S, et al. Direct and immune-mediated cytotoxicity of interleukin-21 contributes to antitumor effects in mantle cell lymphoma. Blood. 2015;126(13):1555-1564.

74. Moroz A, Eppolito C, Li Q, Tao J, Clegg CH, Shrikant PA. IL-21 enhances and sustains CD8+ T cell responses to achieve durable tumor immunity: comparative evaluation of IL-2, IL-15, and IL-21. J Immunol. 2004;173(2):900-909.

75. Atkins MB, et al. High-dose recombinant interleukin 2 therapy for patients with metastatic melanoma: analysis of 270 patients treated between 1985 and 1993. J Clin Oncol. 1999;17(7):2105-2116.

76. Legha SS, et al. Development of a biochemotherapy regimen with concurrent administration of cisplatin, vinblastine, dacarbazine, interferon alfa, and interleukin-2 for patients with metastatic melanoma. J Clin Oncol. 1998;16(5):1752-1759.

77. McDermott DF, et al. Randomized phase III trial of high-dose interleukin-2 versus subcutaneous interleukin-2 and interferon in patients with metastatic renal cell carcinoma. J Clin Oncol. 2005;23(1):133-141.

78. McLane LM, Abdel-Hakeem MS, Wherry EJ. CD8 T cell exhaustion during chronic viral infection and cancer. Annu Rev Immunol. 2019;37:457-495.

79. Kim PS, Ahmed R. Features of responding T cells in cancer and chronic infection. Curr Opin Immunol. 2010;22(2):223-230.

80. Ribas A, Wolchok JD. Cancer immunotherapy using checkpoint blockade. Science. 2018;359(6382):1350-1355.

81. Sakuishi K, Apetoh L, Sullivan JM, Blazar BR, Kuchroo VK, Anderson AC. Targeting Tim-3 and PD-1 pathways to reverse T cell exhaustion and restore antitumor immunity. J Exp Med. 2010;207(10):2187-2194.

82. Jin HT, et al. Cooperation of Tim-3 and PD-1 in CD8 T-cell exhaustion during chronic viral infection. Proc Natl Acad Sci USA 2010;107(33):14733-14738.

83. Siddiqui I, et al. Intratumoral $\mathrm{Tcf} 1^{+} \mathrm{PD}-1^{+} \mathrm{CD} 8^{+} \mathrm{T}$ cells with stem-like properties promote tumor control in response to vaccination and checkpoint blockade immunotherapy. Immunity. 2019;50(1):195-211.e10

84. Vodnala SK, et al. T cell stemness and dysfunction in tumors are triggered by a common mechanism. Science. 2019;363(6434):eaau0135.

85. Hamid O, et al. Safety and tumor responses with lambrolizumab (anti-PD-1) in melanoma. NEngl J Med. 2013;369(2):134-144. 
86. Buchbinder EI, et al. Therapy with high-dose Interleukin-2 (HD IL-2) in metastatic melanoma and renal cell carcinoma following PD1 or PDL1 inhibition. J Immunother Cancer. 2019;7(1):49.

87. Lee JH, Ha J, Kim SH, Kim SJ. IL-2 pathway blocking in combination with anti-CD154 synergistically establishes mixed macrochimerism with limited dose of bone marrow cells and prolongs skin graft survival in mice. J Korean Med Sci. 2006;21(6):1005-1011.

88. Naing A, et al. Safety, antitumor activity, and immune activation of pegylated recombinant human interleukin-10 (AM0010) in patients with advanced solid tumors. J Clin Oncol. 2016;34(29):3562-3569.

89. Chapuis AG, et al. Combined IL-21-primed polyclonal CTL plus CTLA4 blockade controls refractory metastatic melanoma in a patient. J Exp Med. 2016;213(7):1133-1139.

90. Floros T, Tarhini AA. anticancer cytokines: biology and clinical effects of interferon- $\alpha 2$, interleukin (IL)-2, IL-15, IL-21, and IL-12. Semin Oncol. 2015;42(4):539-548.

91. Conlon KC, et al. Redistribution, hyperproliferation, activation of natural killer cells and CD8 T cells, and cytokine production during first-in-human clinical trial of recombinant human interleukin-15 in patients with cancer. J Clin Oncol. 2015;33(1):74-82. 